Article

\title{
Design of Stirrer Impeller with Variable Operational Speed for a Food Waste Homogenizer
}

\author{
Idris A. Kayode ${ }^{1}$, Emmanuel O. B. Ogedengbe ${ }^{1, *}$ and Marc A. Rosen ${ }^{2}$ \\ 1 Energhx Research Group, 353 Faculty of Engineering, Department of Mechanical Engineering, \\ University of Lagos, Akoka-Yaba, Lagos 101017, Nigeria; research@energhx.com \\ 2 Faculty of Engineering and Applied Science, University of Ontario Institute of Technology, \\ 2000 Simcoe Street North, Oshawa, ON, L1H 7K4, Canada; marc.rosen@uoit.ca \\ * Correspondence: ogedengbe@energhx.com; Tel.: +234-703-668-9827
}

Academic Editor: Andrew Kusiak

Received: 10 February 2016; Accepted: 11 May 2016; Published: 20 May 2016

\begin{abstract}
A conceptualized impeller called KIA is designed for impact agitation of food waste in a homogenizer. A comparative analysis of the performance of KIA is made with three conventional impeller types, Rushton, Anchor, and Pitched Blade. Solid-liquid mixing of a moisture-rich food waste is simulated under various operational speeds, in order to compare the dispersions and thermal distributions at homogenous slurry conditions. Using SolidWorks, the design of the impellers employs an Application Programming Interface (API) which acts as the canvas for creating a graphical user interface (GUI )for automation of its assembly. A parametric analysis of the homogenizer, at varying operational speeds, enables the estimation of the critical speed of the mixing shaft diameter and the deflection under numerous mixing conditions and impeller configurations. The numerical simulation of the moisture-rich food waste (approximated as a Newtonian carrot-orange soup) is performed with ANSYS CFX v.15.0. The velocity and temperature field distribution of the homogenizer for various impeller rotational speeds are analyzed. It is anticipated that the developed model will help in the selection of a suitable impeller for efficient mixing of food waste in the homogenizer.
\end{abstract}

Keywords: food waste homogenizer; mixing; impeller; operational speed; critical speed; food waste; Shaft diameter

\section{Introduction}

Municipal solid waste management (MSWM) is an important issue, especially in developing countries like Nigeria due to its adverse environmental effects [1]. Food waste accounts for almost half of the refuse of a standard household in Abuja municipality, according to a 2004 study by Nigeria's Federal Ministry of Environment (see Appendix A) of five districts in Abuja. That study shows that large quantities of mostly organic waste, which is comprised mainly of food and yard waste in household refuse generated annually [1]. In recent years, the amount of food waste generated daily in Hong Kong has shown an increasing trend, from 3155 tons in 2002 to 3584 tons in 2011, accounting for almost $40 \%$ of the MSW [2]. Most of the food waste in Hong Kong is from the domestic sector, accounting for about $70 \%$ of the total food waste, while the remaining $30 \%$ is from the commercial and industrial sector [3].

Ogedengbe et al. [4] conducted an energy audit of the 2001 cafeteria of the University of Lagos, where the monthly food waste was estimated at $1982 \mathrm{~kg}$. It was determined that this quantity of food waste is equivalent to about $200 \mathrm{~m}^{3}$ of methane gas, if processed. Using a carrot-orange soup as the operating fluid (with its thermofluid properties), and assuming constant density and temperature-dependent viscosity in a follow-up numerical investigation, the velocity and temperature 
field distribution under the influence of the mixing source term were presented. However, the mixing source term in the computational fluid dynamics (CFD) model was approximated by a linearized mathematical function of the force impact of the impeller on the fluid [5]. Meanwhile, mechanically agitated homogenizing tanks have been widely used in chemical, biochemical and pharmaceutical industries [6]. The performance of the homogenizer depends on geometric configurations and operating parameters, such as the impeller rotational speed and height of fluid in the homogenizer.

Mixing plays an important role in the homogenization of food waste. The fundamental mechanism involves physical movement between various parts of the entire mass with rotating impeller blades, which are designed to breakdown and blend the heterogeneous food waste into a slurry. Therefore, a detailed knowledge of velocity, temperature distribution and power requirements of the homogenizer are required. Over the years many engineering design principles have been developed, and the design of mixing equipment for a desired process objective has been possible and an imperative [7].

Jirout and Rieger [8] experimentally assessed the effect of impeller design on mixing suspensions, for various impellers and calculated the critical impeller speed and power consumption necessary for off-bottom suspension of solid particles. Aqueous suspensions of glassy beads with large range of volumetric concentrations $C_{v}$ and mean volumetric diameter $d_{p}$ were used to model the suspension. The results suggest that Pitched Blade impellers have higher suspension efficiencies, compared to other impeller configurations. Rajeev et al. [9] investigated the mixing of rheological complex fluids using flat bladed impellers as close clearance agitators in the laminar regime. The non-Newtonian fluids were adequately described by the power-law model with a flow index $n$ between 0.1 and 0.4 . Power draw analysis was used to explore the combined influence of pseudo-plasticity and impeller geometry. The effective shear rate $\left(K_{s}\right)$ was determined using the modified Couette analogy. The power curve method and direct calculation method agreed with the hypothesis of $K_{s}$, being independent of the flow index. The effect of impeller shape on off-bottom particle suspension was also investigated by Rieger et al. [10]. Based on numerous measurements, empirical correlations were proposed for the just-suspended impeller speeds for various impeller types. That investigation demonstrated that the standard Pitched Blade impeller has the highest power consumption while the Pitched Blade impeller has a higher efficiency for particle suspension. Monteith et al. [11] used the tracer method to analyze the effect of mixing in full scale anaerobic digesters and showed that the dead zones accounts for about $77 \%$ of the volume theoretically available for mixing, thus reducing the hydraulic retention time.

Computational fluid dynamics (CFD) provides a flexibility and an inexpensive way of examining the impact of modifying vessel configuration and dimensions, impeller orientation and rotational speed, and fluid properties. Abbaszadeh et al. [12] employed a combination of the finite element method (FEM) and an analytical technique in the design of mixing systems in a stirred tank reactor for bio-diesel production. The design was based on a Pitched Blade turbine down flow with two inclined blades $\left(45^{\circ}\right)$, assuming maximum working conditions. The mixing power, mechanical design and stress analysis of the agitator were captured as source terms within the FEM models. The results showed a similarity between the analytical and modal analysis of the critical rotational speed of the mixing shaft, with basic dimensions and materials considered for the design of the mixing system in acceptable range. Asiri et al. [13] proposed designs for differential agitators and implementation methods in order to maximize agitation. A parametric study and shape optimization, for various material properties and loading conditions, was carried out with numerical analysis. Using ANSYS, the optimum design for the geometrical parameters of the differential agitator elements were obtained, while the performance of a normal agitator was compared with the differential type. It was observed that the differential type agitator exhibited better homogeneity.

Mixing is a complicated process especially because of the multiphase turbulence during mixing and the design of a mixer [14]. Although, CFD can be used to improve understanding, it suffers from the disadvantage of a high computation cost when complex chemistries with large number of species are involved [15]. CFD based approaches are extensively used under such constraints, and have provided reasonable predictions at reduced computation expense for a single phase system [15]. 
Delaplace et al. [16] numerically simulated the heat transfer of highly viscous Newtonian fluids at unsteady state in a jacketed vessel using CFD. The numerical results exhibited good agreement with the experimental values of some features, but there were discrepancies wtih the local thermal boundary layer and the global heat transfer measured experimentally.

Ghani et al. [17] investigated the thermal sterilization rate when a can containing viscous carrot-orange soup was rotated at $10 \mathrm{rpm}$. The result showed that the combined natural and forced convection split the slowest heating zone into two regions. The extremely high viscosity of the carrot-orange soup (or a moisture-rich food) guaranteed a relatively small shear rate regime, where a Newtonian fluid assumption becomes possible. Although experimental and numerical studies of mixing systems are ongoing, no impeller has been designed for the mixing of moisture-rich food waste due to the complex rheology of the non-Newtonian fluid (without carrot-orange soup assumptions) [18].

In this paper, a conceptualized impeller called KIA is designed for homogenizing food waste. The KIA impeller is modeled to serve a dual purpose: grinding the heterogenous food waste and subsequent conversion into a slurry. The food waste slurry in the homogenizer is continously stirred for a maximum of two weeks to prevent sedimentation before it is fed to a gasifier for thermochemical processing, carrot soup is used as the moisture rich food waste and assumed to have constant properties except for viscosity (temperature dependent) and density, in order to adopt a Newtonian approximation due to its low shear rate, as used in many studies [5,19]. Using a single phase flow field for simplicity in the simulation of the fluid, a comparison of the performance of the KIA impeller with conventional impeller types, including Rushton, Anchor and Pitched Blade, is made using ANSYS CFX v.15.0 for the different homogenizer speeds. It is anticipated that the strategic parametric analysis of the KIA impeller will offer a cost-effective mixing in terms of power consumption, quantity and quality of yield.

\section{Methodology}

Figure 1 shows a typical set-up with the impeller for agitation of food waste. Material selection for the impeller shaft is based on two distinct factors, torque and bending moment, and the critical speed of the impeller shaft. The various impeller configurations investigated are modeled using Solidworks CAD software, as shown in Figures 2-5. The governing equations for the transport of the moisture-rich food waste are approximated using the continuity, momentum and the energy equations with the continuum assumption.

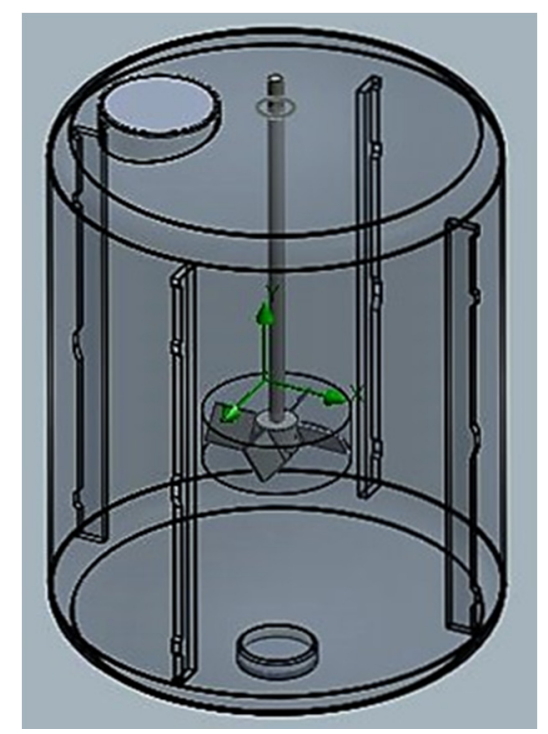

Figure 1. Typical homogenizing system with impeller. 


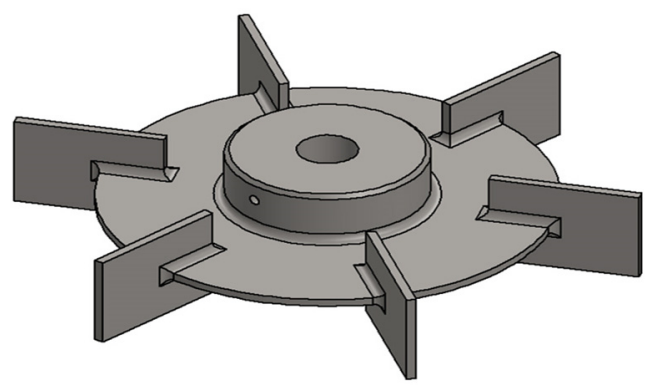

Figure 2. Six (6) bladed Rushton impeller.

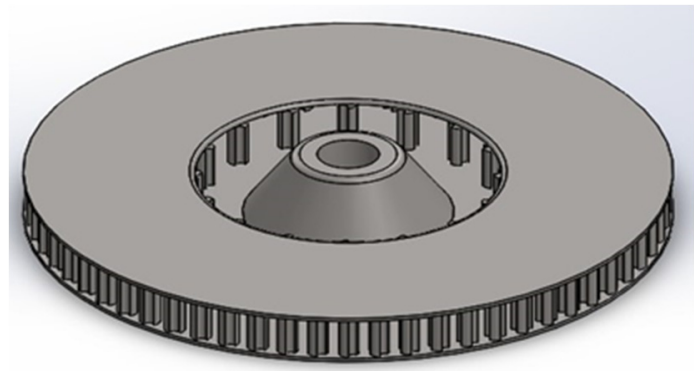

Figure 3. KIA impeller.

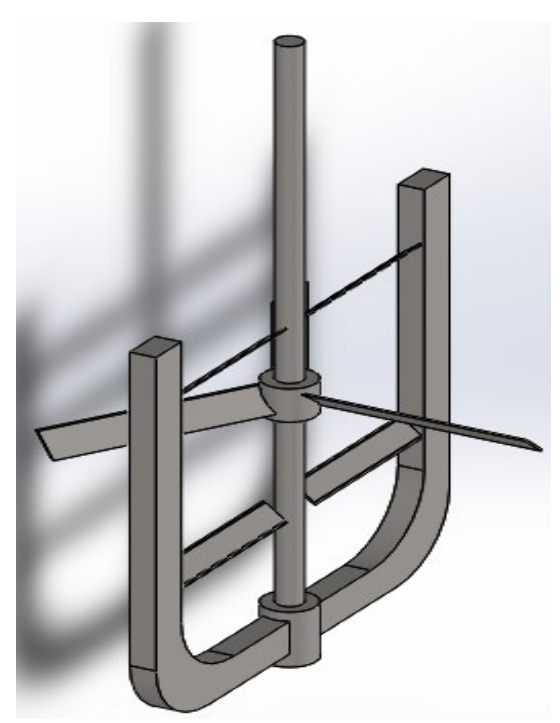

Figure 4. Anchor impeller.

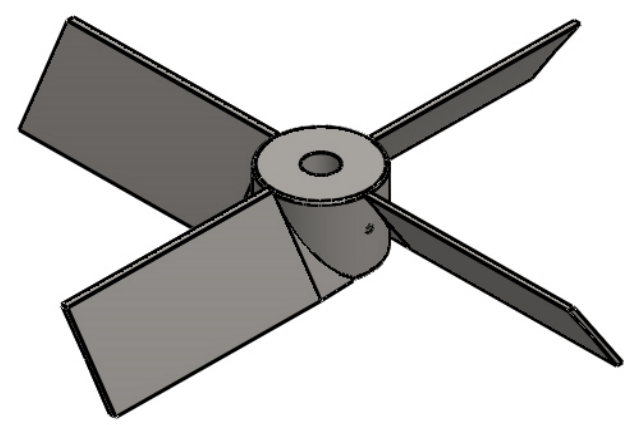

Figure 5. Pitched Blade impeller. 


$$
\begin{gathered}
\frac{\partial \rho}{\partial t}+\frac{\partial\left(\rho u_{i}\right)}{\partial x_{i}}=0 \\
\frac{\partial\left(\rho u_{i}\right)}{\partial t}+\frac{\partial\left(\rho u_{i} u_{j}\right)}{\partial x_{j}}=-\frac{\partial P}{\partial x_{i}}+\frac{\partial}{\partial x_{j}}\left[\mu\left(\frac{\partial u_{i}}{\partial x_{j}}+\frac{\partial u_{j}}{\partial x_{i}}-\frac{2}{3} \frac{\partial u_{k}}{\partial x_{k}} \delta_{i j}\right)\right]+\rho g_{i}+F_{i} \\
\frac{\partial(\rho E)}{\partial t}+\frac{\partial}{\partial x}\left(u_{i}(\rho E+p)\right)=\frac{\partial}{\partial x_{i}}\left(k_{e f f} \frac{\partial T}{\partial x_{i}}-\sum_{j} h_{j} J_{j, t}+u_{j}\left(\tau_{i j}\right)_{e f f}\right)+S_{h}
\end{gathered}
$$

Using a multiple reference frame (MRF) approach [20] to simulate the impeller rotation, the computational domain is divided into two regions: An inner region (rotating frame), which encompasses the impeller, and an outer region (stationary frame), which includes the homogenizer vessel wall, baffles and the flow outside the impeller frame. In the former, the governing equations are solved in the rotating framework. In the latter, the equations are solved in the stationary framework. The boundary needs to be selected in such a way that the predicted results are not sensitive to its actual location. In the present case, the interface between the rotating and stationary regions was set between the impeller tip and the edge of the baffles in the radial direction and one impeller blade width above and below the impeller blades. The computational models and their mathematical expressions used in this study are described further in Reference [21].

\subsection{Homogenizer Configuration}

The solution domain consists of a cylindrical conical shaped bottom tank of diameter $(\mathrm{T})$ of $2000 \mathrm{~mm}$, height $(\mathrm{H})$ of $2500 \mathrm{~mm}$ and volume $(\mathrm{V})$ of $6.078 \mathrm{~m}^{3}$. The impeller dimensions used for this study are shown in Table 2. The tank configuration for the Pitched Blade, KIA and the 6 bladed Rushton impellers are equipped with 4 baffles all equally spaced at $90^{\circ}$ around the tank periphery, while a tank geometry having no baffles is used for the Anchor impeller. Mixing is caused by mechanical agitation of the impellers which are driven by a prime mover with impeller speeds of 100-600 rpm. For the baffled tank geometry, each impeller has a diameter (D) of $T / 3$ and $T / 1.02$ for the Anchor impeller which is a close clearance impeller. The impellers are mounted on a shaft concentric with the axis of the homogenizer vessel with the bottom impeller having an off-bottom clearance $(C)$ of $T / 3$, which is below the geometric centre of the containing vessel. The impeller design is carried out with Solidworks and imported into the ANSYS CFX environment for simulation. The properties of the carrot-orange

\begin{tabular}{|c|c|c|c|}
\hline Fluid/Impeller Material & Density $\left(\mathrm{kg} / \mathrm{m}^{3}\right)$ & $\begin{array}{l}\text { Specific Heat Capacity } \\
\left(\mathrm{J} \cdot \mathrm{kg}^{-1} \cdot \mathrm{K}^{-1}\right)\end{array}$ & $\begin{array}{l}\text { Thermal Conductivity } \\
\left(\mathrm{W} \cdot \mathrm{m}^{-1} \cdot \mathrm{K}^{-1}\right)\end{array}$ \\
\hline Carrot-Orange Soup & 1026 & 3880 & 0.596 \\
\hline Stainless Steel & 8000 & 500 & 16.3 \\
\hline
\end{tabular}
soup and the impeller [22], as used for simulation in the ANSYS environment are shown in Table 1.

Table 1. Thermophysical properties of homogenizing system.

The geometrical dimensions of the homogenizer vessel and impellers used for this study are shown in Figure 6. The simulations are carried out at impeller rotational speeds of 100-600 rpm, corresponding to a Reynolds number between $66.78 \times 10^{3}$ to $400.76 \times 10^{3}$ for all baffled homogenizer vessels and values ranging from $638.2 \times 10^{3}$ to $3.83 \times 10^{6}$ for the Anchor impeller (for the carrot-orange soup dynamic viscosity of $0.6 \mathrm{~kg} / \mathrm{ms}$ ). 

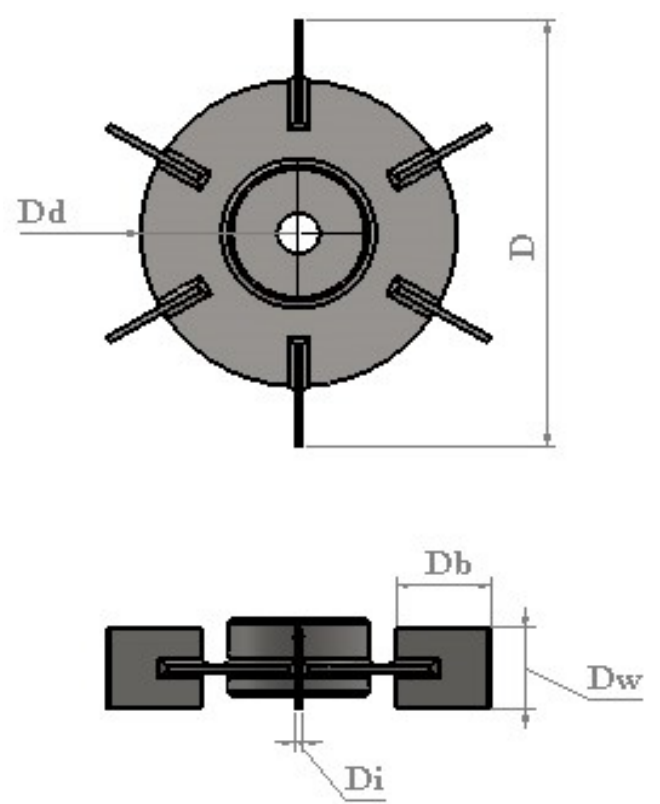

(a)

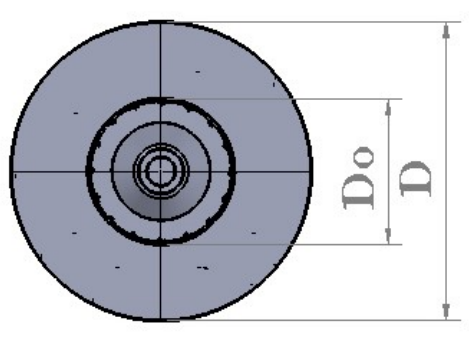

(c)
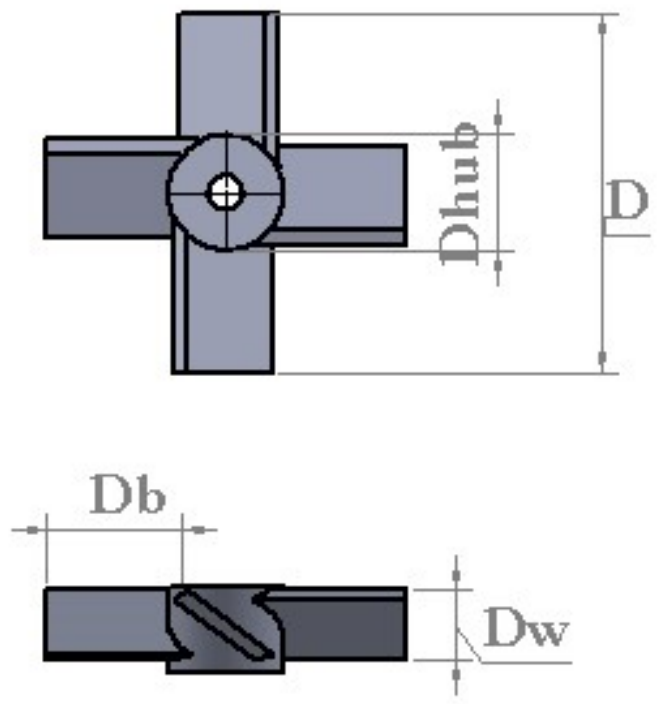

(b)

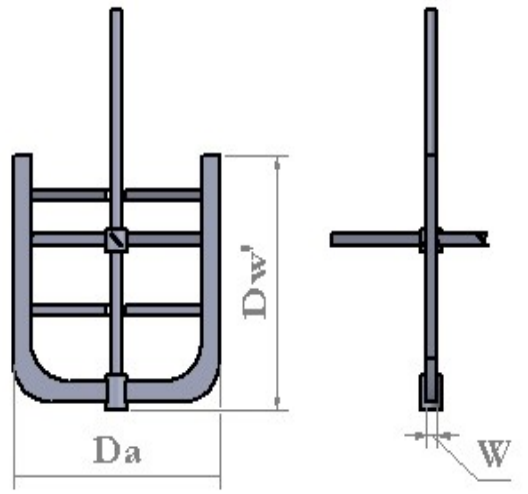

(d)

Figure 6. Orthographic views of impeller with dimensions. (a) Six (6) bladed Rushton impeller (b) Pitched Blade impeller (c) KIA impeller (d) Anchor impeller

Table 2. Impeller dimension used in simulation.

\begin{tabular}{ccc}
\hline Dimension & Symbol & Value (mm) \\
\hline Impeller diameter & $\mathrm{D}$ & 625 \\
Blade length & $\mathrm{Db}$ & 145 \\
KIA impeller inner diameter & $\mathrm{Do}$ & 305 \\
Pitched Blade hub diameter & $\mathrm{D}_{\mathrm{hub}}$ & 200 \\
Blade height & $\mathrm{Dw}$ & 30 \\
KIA impeller plate thickness & $\mathrm{W}$ & 65 \\
Impeller plate diameter & $\mathrm{Dd}$ & 450 \\
Anchor impeller diameter & $\mathrm{Da}$ & 1932 \\
Anchor impeller height & $\mathrm{Dw}^{\prime}$ & 2000 \\
\hline
\end{tabular}

\subsection{Computational Method}

The symmetry assumption enables the use of half of the geometry in the simulation in order to reduce the required time $\left(t_{c p u}\right)$ for numerical computation. ANSYS ICEM CFD 15.0 provides the capability for meshing the computational domain, thereby presenting the flexibility for creating and modifying the geometry of the homogenizer vessel and the impellers for the parametric analysis. 
A mesh was created to discretize the domain into small control volumes, where the conservation equations are approximated by algebraic equations. The mesh for the homogenizer simulation set-up contains three major domains (Fluid, Homogenizer vessel and Impeller) each having different global mesh statistic results, such as nodes, elements, tetrahedrons and prisms [21]. Grid sensitivity has been avoided by generating different mesh densities results revealing grid independence, Figure 7 shows the different mesh regions of the homogenizer.

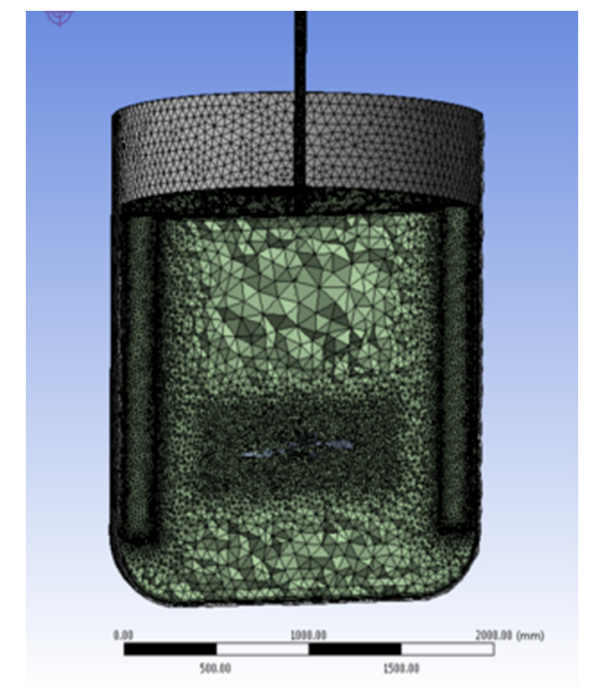

Figure 7. 3-Dimensional unstructured mesh with tetrahedral and prismatic elements for homogenizer simulation.

To account for the viscous nature of the fluid (carrot-orange soup) the following boundary conditions and assumptions are adopted for the simulations. A non-slip condition is used on all solids (baffles, homogenizer vessel, impeller and shaft), so that the fluid has a zero velocity at the homogenizer wall. In the free surface of the fluid, shear streses and the axial velocity are zero and a flat surface is assumed; therefore, a free-slip surface condition on the upper surface of the homogenizer vessel is also applied. It is assumed further that the fluid (carrot-orange soup) has an initial temperature of $28^{\circ} \mathrm{C}$ and the homogenizer wall is heated at a constant temperature of $60^{\circ} \mathrm{C}$.

ANSYS CFX uses a coupled solver, which solves the hydrodynamic equations for the field variables $(\mathrm{u}, \mathrm{v}, \mathrm{w}$, and $\mathrm{p})$ as a single system. This solution approach uses a fully implicit scheme for the discretization of the equations at any given time step. For steady-state problems, the time-step behaves like an 'acceleration parameter', to guide the approximate solutions in a physically based manner to a steady-state solution. This reduces the number of iterations required for convergence to a steady-state, or to calculate the solution for each time step in a time-dependent analysis [22].

The impeller represents an immersed solid object within the solution domain as shown in Figure 8, whose impact is modeled as a source term in the governing transport equations, i.e.,

$$
\begin{gathered}
S_{X}=-\propto \beta C\left(U_{X}-U_{X}^{F}\right) \\
S_{y}=-\propto \beta C\left(U_{y}-U_{y}^{F}\right) \\
S_{Z}=-\propto \beta C\left(U_{Z}-U_{Z}^{F}\right)
\end{gathered}
$$

where $U_{X}, U_{y}$, and $U_{Z}$ are the three components of fluid velocity and $U_{X}^{F}, U_{y}^{F}$, and $U_{Z}^{F}$ are the components of the forcing velocity due to the immersed solid. The momentum source coefficient $-C$ is a large number, and is evaluated as the average of the three diagonal coefficient in the momentum 
equation. The presence of an immersed solid (impeller) in the flow field is modeled through a special $\beta$ forcing function. The ANSYS computational fluid dynamics software (CFX solver) automatically updates the mesh positions of the immersed solid at the beginning of each time step, and then sets up a list of fluid nodes that lie inside the immersed solid in order to drive the fluid velocity towards the immersed solid velocity.

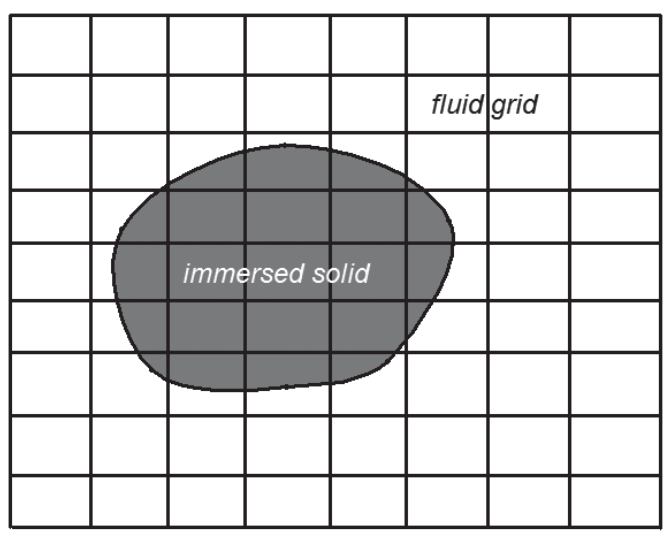

Figure 8. Schematics of an immersed solid in a 2-D fluid grid.

\section{Results and Discussions}

The performance of the stirring process in the homogenizer and the distribution of heat from the boundary layer (homogenizer-wall) are influenced by the turbulence level and the fluid bulk flow [23]. The level of heat transfer transported between the mixed and unmixed zone flow regimes is dependent on the mean velocity of the impeller.

\subsection{Homogenizer with Rushton Impeller}

The Rushton impeller is a high speed radial flow impeller. Due to its high shear levels, this stirrer is primarily used for blending, improving heat transfer, and gas dispersion processes. During mixing using a Rushton impeller, the flow is accelerated in a radial direction and deflected at the vessel wall into an upper and lower recirculation loop. It is effective for both low and high viscosity fluids but in the latter case the fluid flow is primarily tangential. Most of the mass and momentum transfer occurs in the vortex core due to high levels of turbulence within the circulation regions, as shown in Figure 9, resulting in high degree of mixing especially in the primary circulation loop. The power dissipation (shear) rate is concentrated at the blade tips [24] and is not uniformly distributed throughout the homogenizer. The unbalanced shear distribution possibly enhances heterogeneous mixing of the food waste in the impeller outer region. The turbulent eddy viscosity represents the extent of diffusion (mixing) in the homogenizer, as seen on the color codes in Figure 9, the blue region indicate stagnant zones (unmixed) in the homogenizer, while the yellow and red regions (cavern) indicate high levels of mixing by the impeller. 


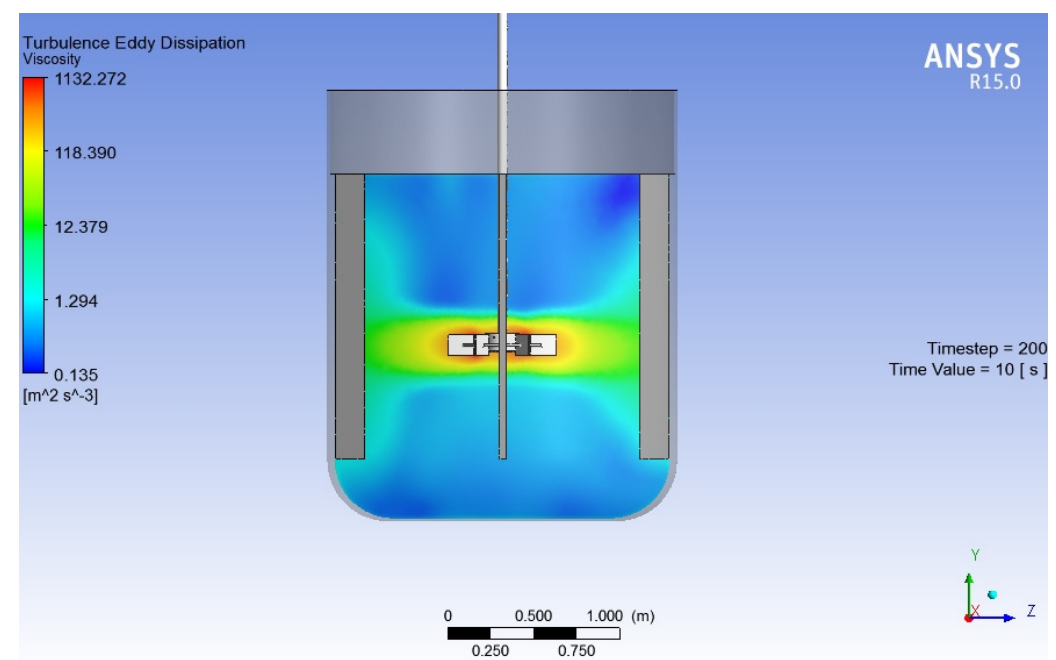

Figure 9. Turbulence eddy dissipation within the Rushton impeller homogenizer.

The primary circulation loop increases as the impeller speed is varied from 100-600 rpm as can be clearly seen from the velocity profile plots in Figures 10 and 11 indicating well stirred regions (cavern) near the impeller and stagnant zones elsewhere in the homogenizer vessel. The solution domain in Figure 10 shows where the diffusive effect (mixing) is greatest (increases from a to $\mathbf{d}$ ) in the area swept by the impeller (cavern) and least at the bottom and top parts of the homogenizer vessel tank. Figure 11 shows the strong interaction between the impeller (increases from a to $\mathbf{d}$ ), the fluid and the baffles interfaces in the ZX plane of the homogenizer. The circulation loop around the Rushton impeller tip increases gradually from 100-600 rpm. This result suggest mass movement of the fluid (mixed zones) around the impeller, which arises as the impeller rotational speed is increased.

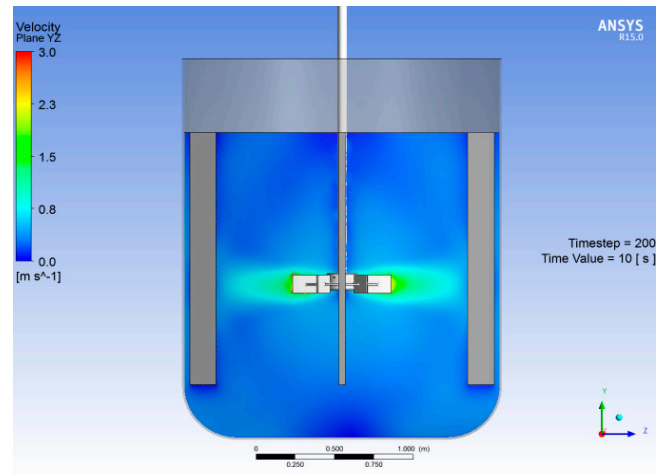

(a) $100 \mathrm{rpm}$

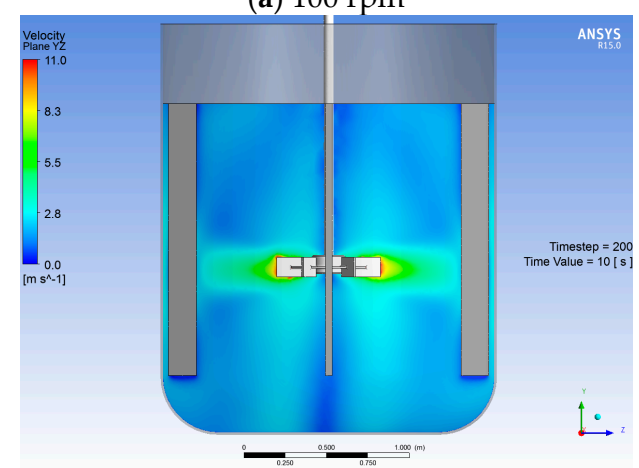

(c) $500 \mathrm{rpm}$

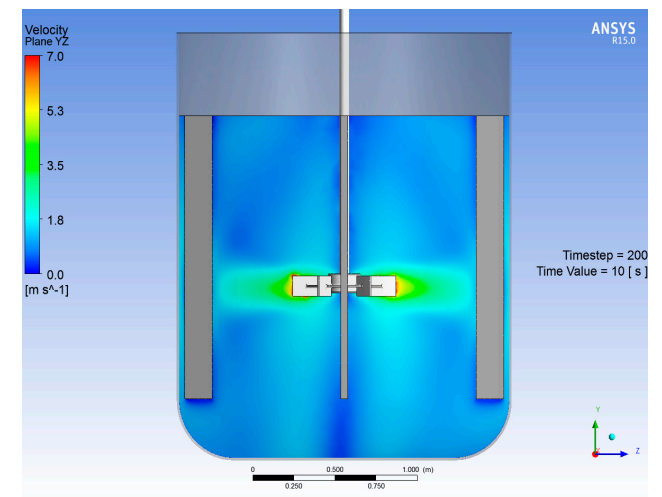

(b) $300 \mathrm{rpm}$

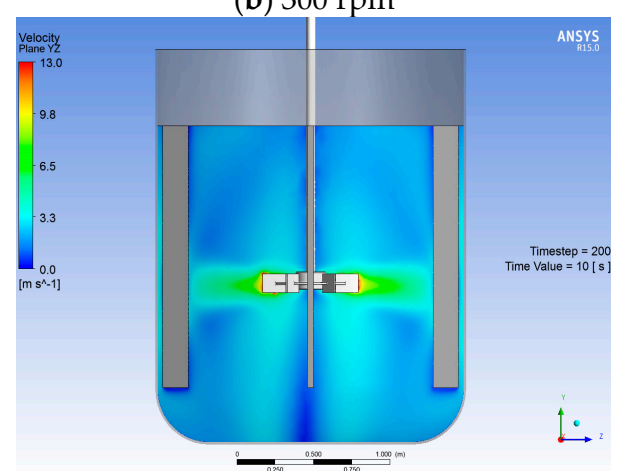

(d) $600 \mathrm{rpm}$

Figure 10. Velocity profiles for 6 blade Rushton impeller YZ plane, for six impeller rotational speeds. 


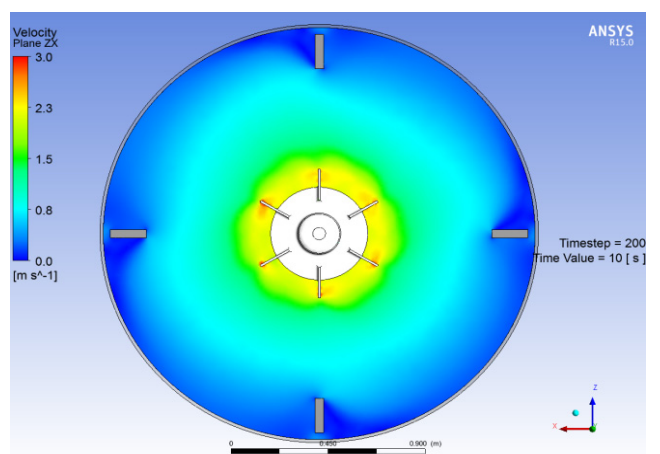

(a) $100 \mathrm{rpm}$

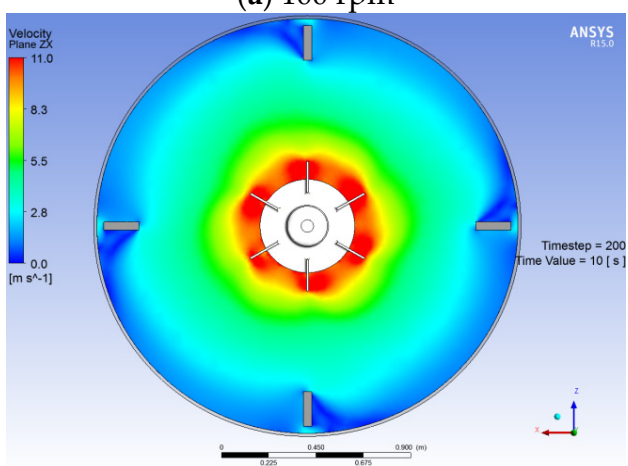

(c) $500 \mathrm{rpm}$

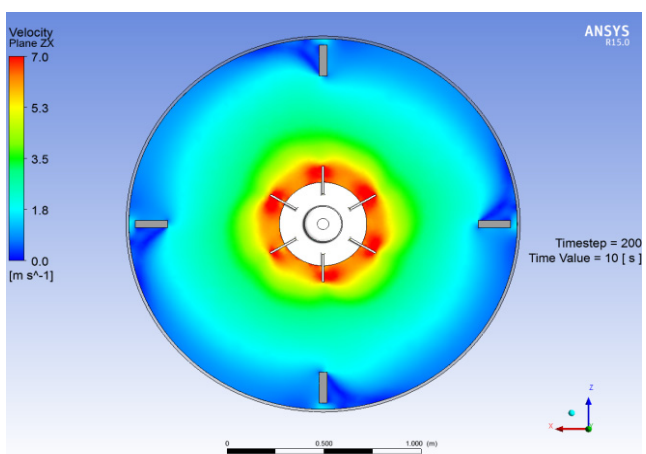

(b) $300 \mathrm{rpm}$

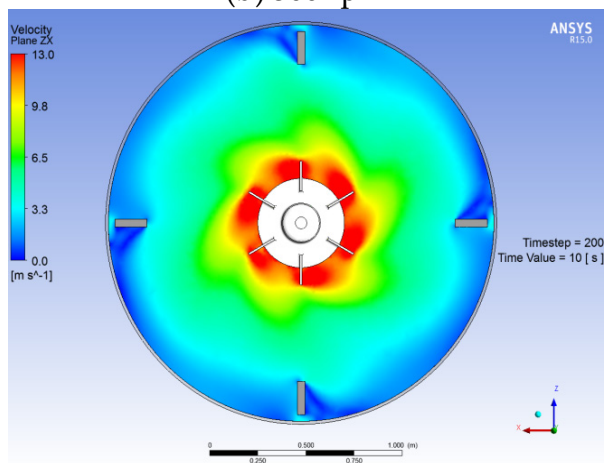

(d) $600 \mathrm{rpm}$

Figure 11. Velocity contour profiles for 6 blade Rushton impeller homogenizer, for six impeller rotational speeds.

Heat dissipation from the homogenizer vessel wall to the fluid domain within the Rushton impeller homogenizer increases as the impeller rotational speed increases from $100 \mathrm{rpm}$ to $600 \mathrm{rpm}$, as seen in Figures 12 and 13 (increases from a to d). The legend on the left hand side of the plot show the extent of heat dissipation from the homogenizer vessel wall by a gradual temperature rise of $0.04 \%$ $(0.132 \mathrm{~K})$ to the fluid domain, which is at an initial temperature of $301 \mathrm{~K}$. This indicates that the food waste is constantly heated at a temperature of $333 \mathrm{~K}$. The steady state flow field is visually displaced in Figure 13, which shows the temperature distribution in the ZX plane. The blue region around the impeller in the homogenizer indicates the "dead zones", where heating and mass transfer of fluid are poor (especially predominant in Figure 13a).

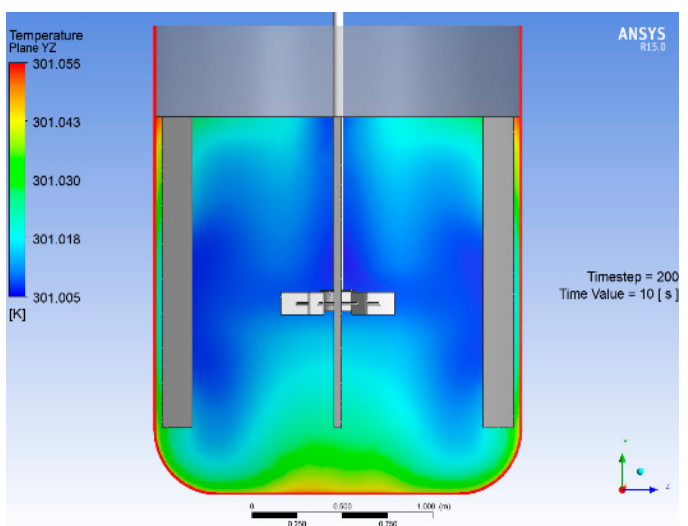

(a) $100 \mathrm{rpm}$

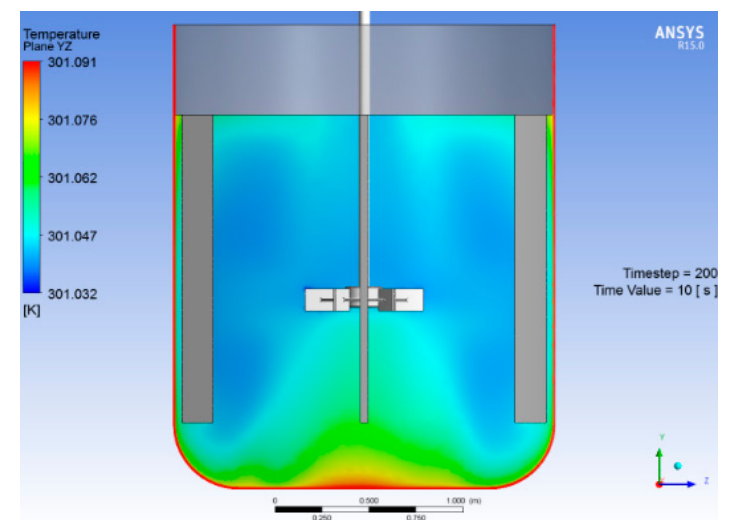

(b) $300 \mathrm{rpm}$

Figure 12. Cont. 


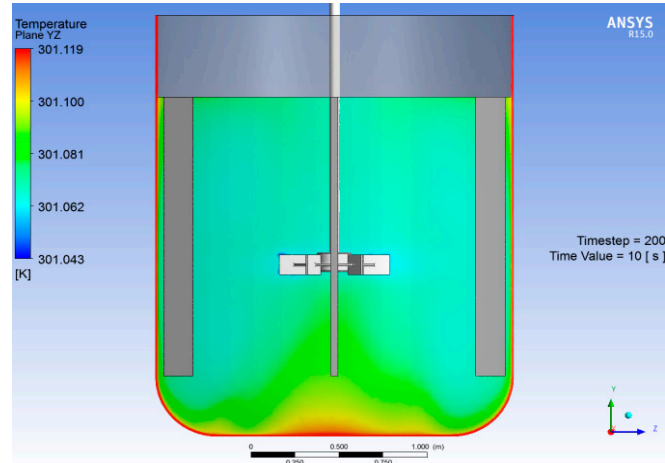

(c) $500 \mathrm{rpm}$

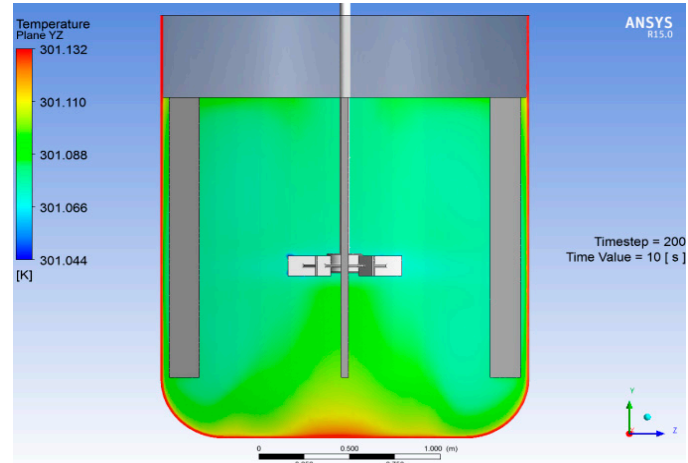

(d) $600 \mathrm{rpm}$

Figure 12. Temperature distributions for Rushton impeller in $\mathrm{YZ}$ plane, for six impeller rotational speeds.

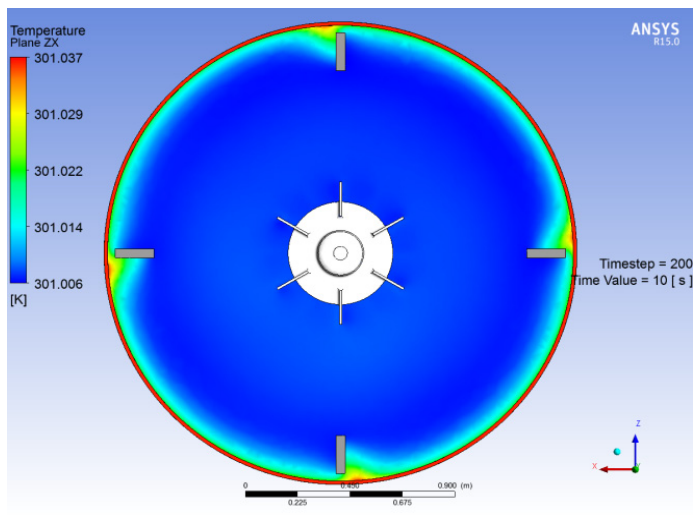

(a) $100 \mathrm{rpm}$

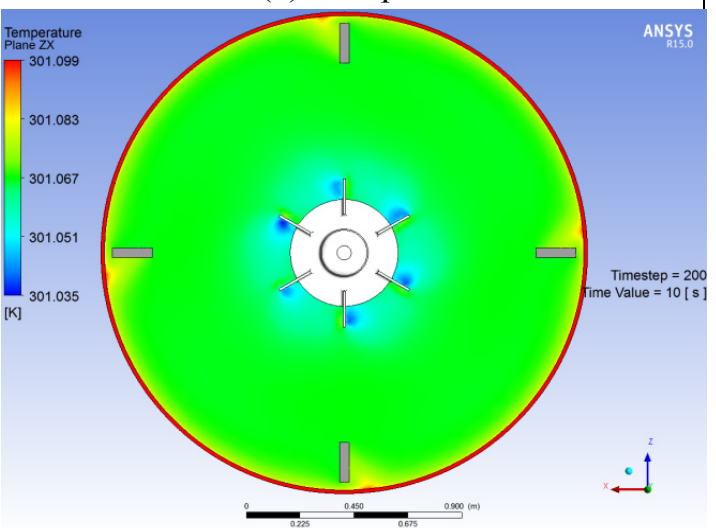

(c) $500 \mathrm{rpm}$

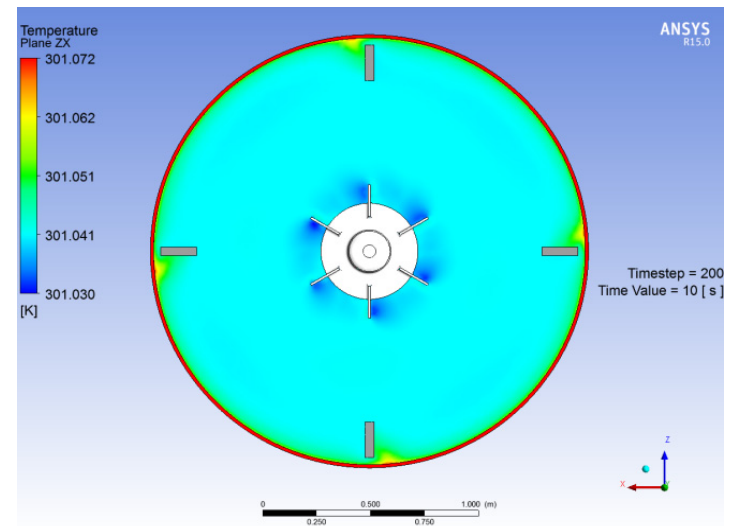

(b) $300 \mathrm{rpm}$

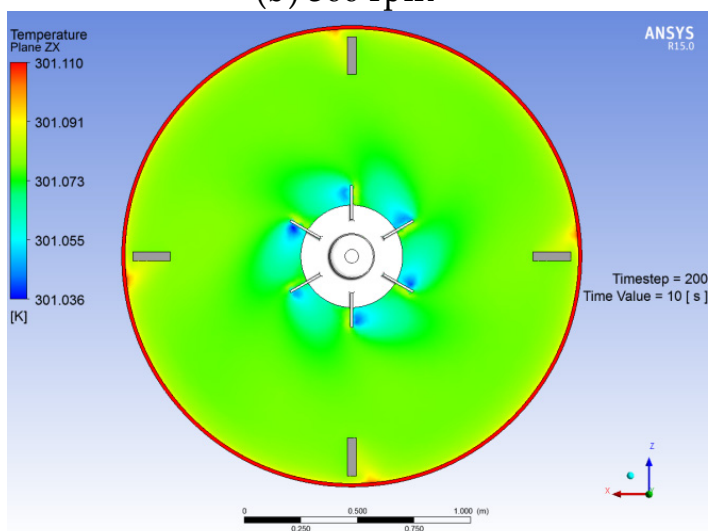

(d) $600 \mathrm{rpm}$

Figure 13. Temperature distributions for 6 blade Rushton impeller homogenizer in ZX plane, for six impeller rotational speeds.

\subsection{Homogenizer with KIA Impeller}

A KIA impeller provides unique flow profiles, compared with the flow patterns of common axial and radial flow impellers. The profile generated by the KIA impeller is similar to that exhibited by mixed flow impellers, as seen in Figure 14. 


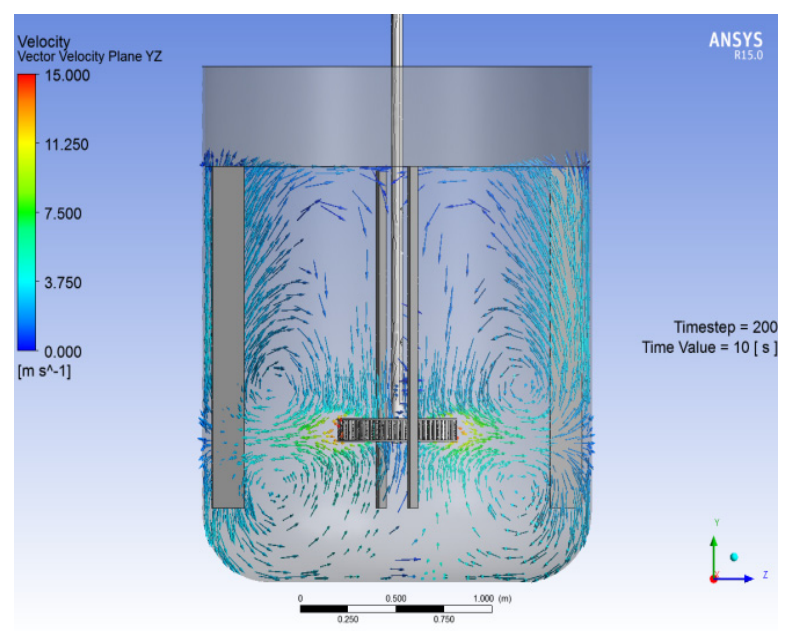

Figure 14. Velocity vector profile of KIA impeller homogenizer.

The KIA impeller is modeled in such a way that it has an inlet for the passage of the moisture-rich food waste through its tapered hub and an outlet through the radial arrangement of the impact rings between the impeller plates which is intended to break up the heterogenous food waste. This characteristic helps to improve the homogeneity of the mixture and the mass flow rate in the homogenizer. Figure 15 shows the velocity profile in the $\mathrm{YZ}$ plane (while the same velocity profile can be viewed in the ZX plane, as shown in Figure 16) with the cavern diameter around the KIA impeller, indicating the area swept by the impeller (mixed zones) and this gradually increases as the rotational speed of the impeller increases from 100 to $600 \mathrm{rpm}$ (increases from a to d). Additionally, it appears that the dead zones decreases in the homogenizer with increasing impeller rotational speed. The velocity contour profile in the ZX plane shows the interaction between the impeller, baffles and the homogenizer vessel wall, the stirred region in the homogenizer having a mean velocity of $3.0 \mathrm{~m} / \mathrm{s}$ at an impeller rotational speed of $100 \mathrm{rpm}$ and a mean velocity of $17.0 \mathrm{~m} / \mathrm{s}$ at an impeller rotational speed of $600 \mathrm{rpm}$. The apparent increase in mean fluid velocity in the homogenizer indicates better heat and mass transfer rates as impeller rotational speed is increased. At the exit of the fluid through the impact rings, there is a transfer of power to the fluid near the impeller which accounts for the viscous loss due to fluid friction; thus there is a maximum viscous dissipation rate near the impeller blade tip and a rapid decrease of it towards the homogenizer wall.

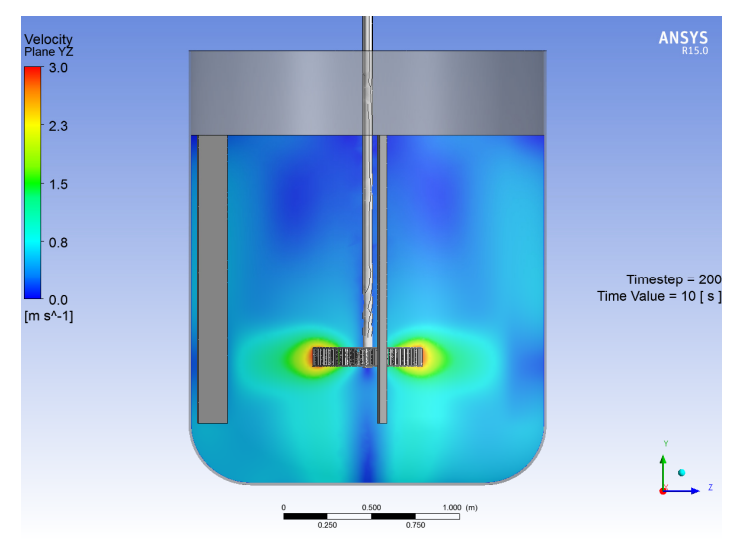

(a) $100 \mathrm{rpm}$

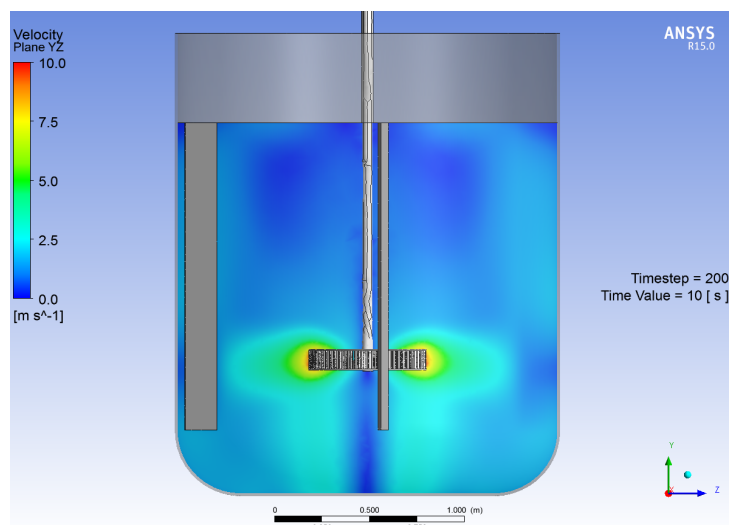

(b) $300 \mathrm{rpm}$

Figure 15. Cont. 


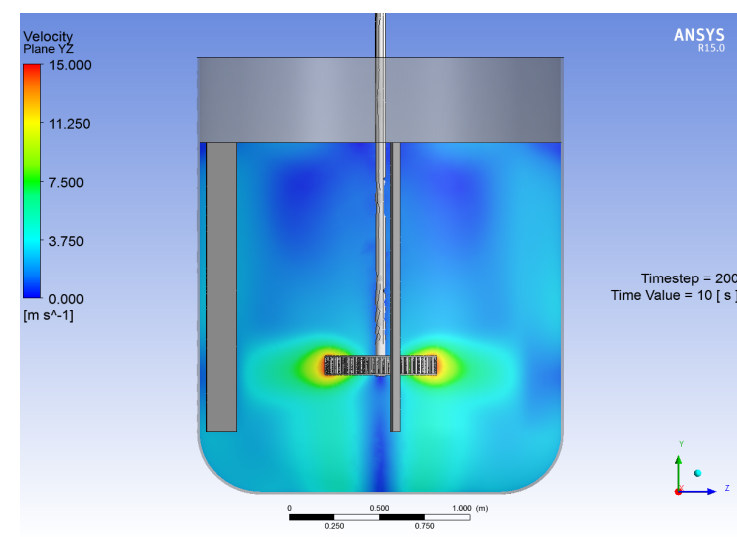

(c) $500 \mathrm{rpm}$

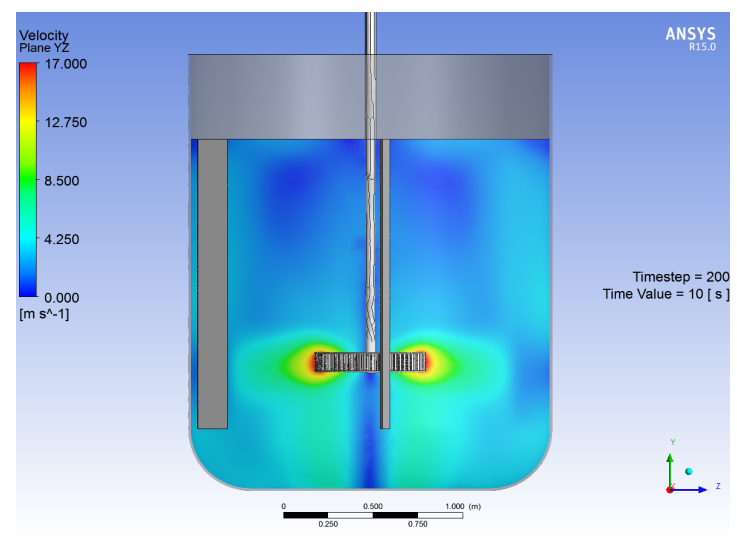

(d) $600 \mathrm{rpm}$

Figure 15. Velocity profiles for KIA impeller homogenizer in YZ plane, for six impeller rotational speeds.

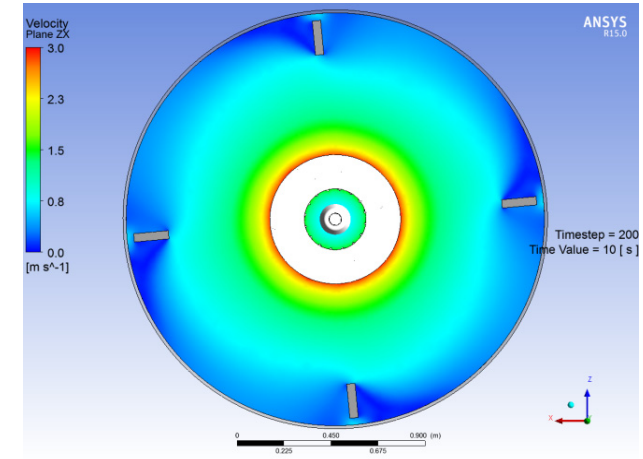

(a) 100rpm

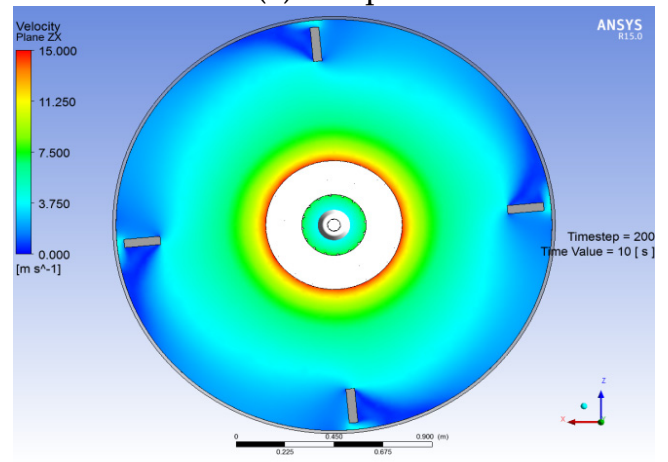

(c) $500 \mathrm{rpm}$

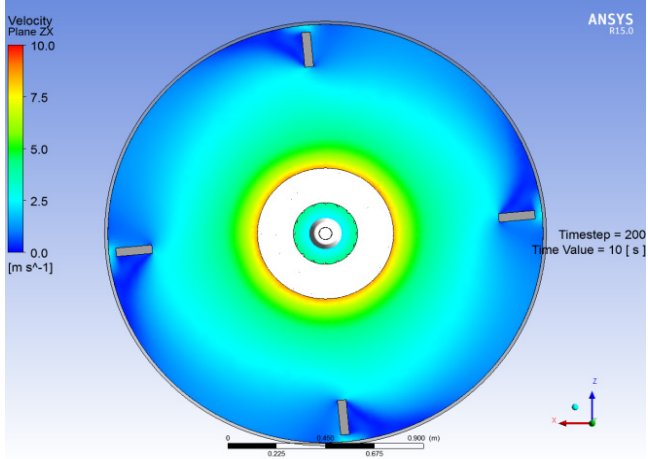

(b) $300 \mathrm{rpm}$

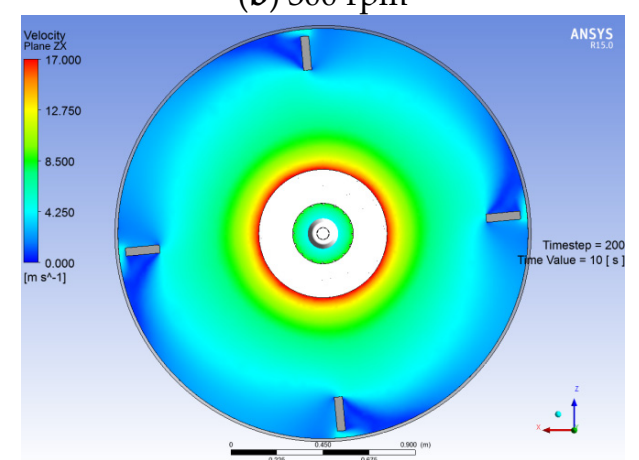

(d) $600 \mathrm{rpm}$

Figure 16. Velocity profiles for KIA impeller homogenizer in ZX plane, for six impeller rotational speeds.

Temperature distributions for the KIA impeller are shown in Figures 17 and 18. It is seen that convective transport for the KIA impeller from the boundary layer (homogenizer wall) to the fluid domain is better when compared to the Rushton impeller, as shown in Figures 12 and 13. This improvement can be attributed to the use of impact rings on the impeller plate. Increasing the rotational speed of the impeller from $100 \mathrm{rpm}$ to $600 \mathrm{rpm}$ increases the homogeneity of the mixture, as expected (increases from a to $\mathbf{d}$ ). Thus, the KIA impeller homogenizer provides better heat and mass transfer rates during mixing, and is expected to provide a much better homogeneity compared to the 6 blade Rushton impeller. Additionally, the superior performance is attributed to the impact rings on the impeller plate, and the baffle-vortex interactions which provides intense flow dispersion inside the homogenizer. 


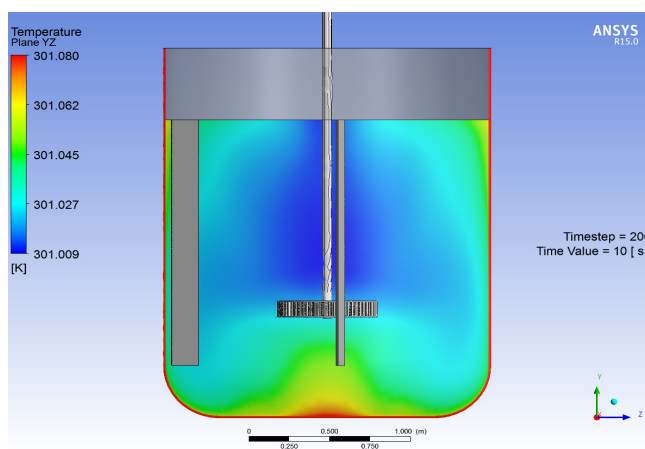

(a) $100 \mathrm{rpm}$

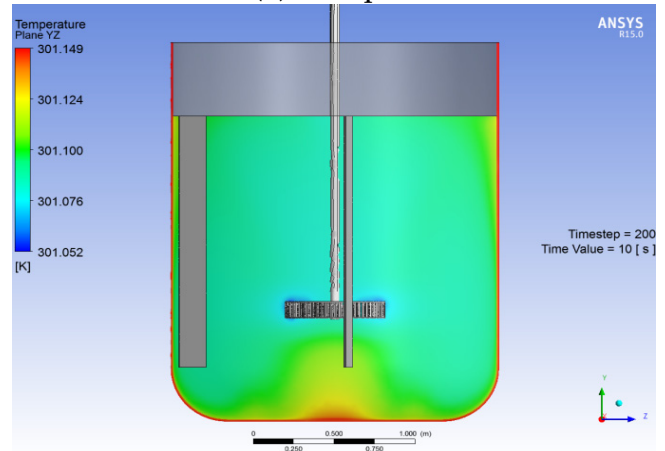

(c) $500 \mathrm{rpm}$

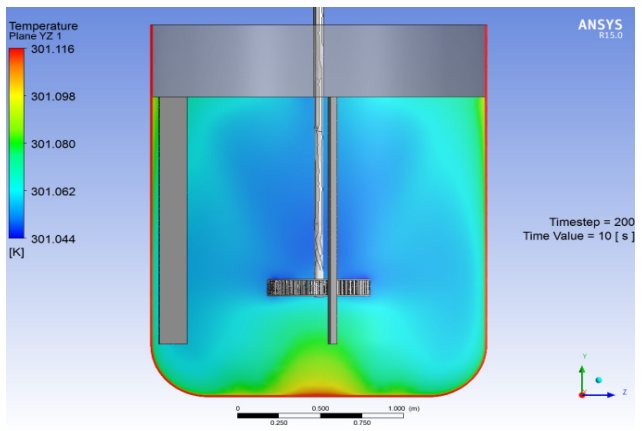

(b) $300 \mathrm{rpm}$

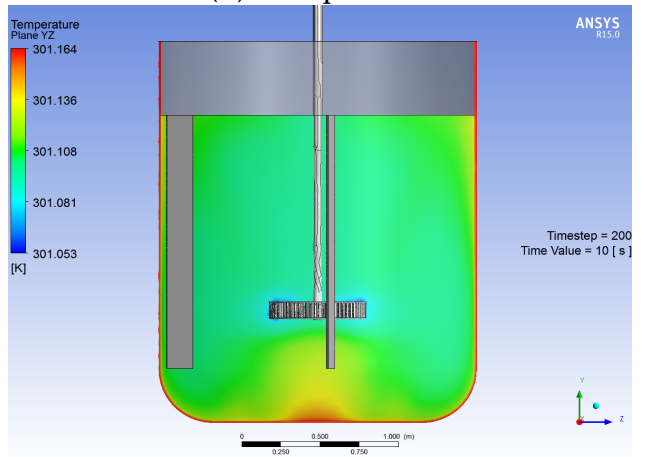

(d) $600 \mathrm{rpm}$

Figure 17. Temperature distributions within the KIA homogenizer in YZ plane, for six impeller rotational speeds.

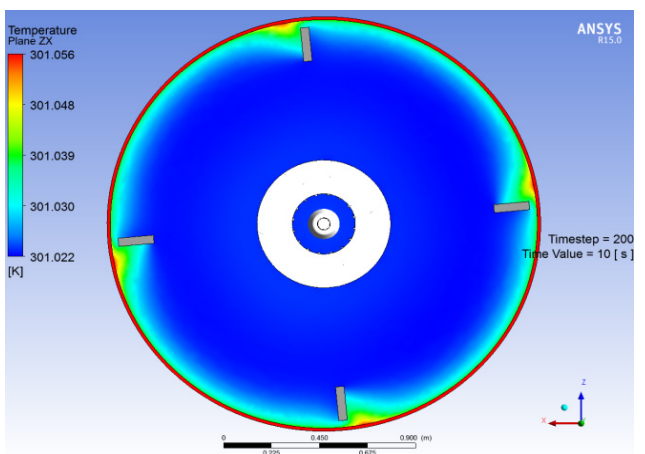

(a) $100 \mathrm{rpm}$

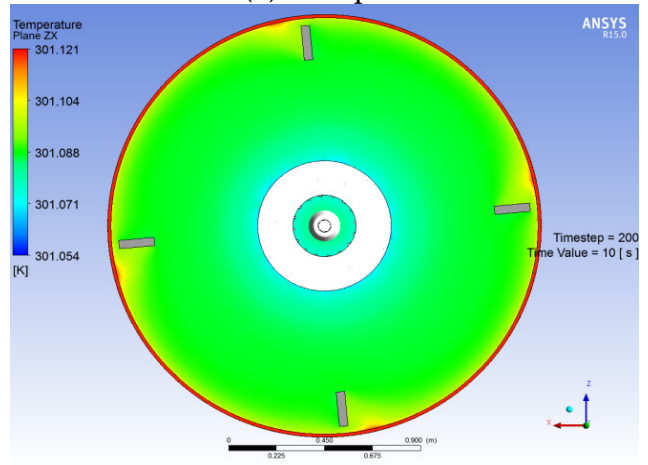

(c) $500 \mathrm{rpm}$

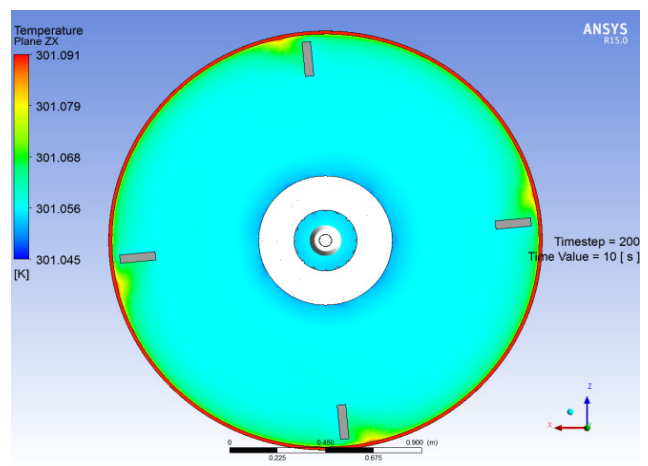

(d) $300 \mathrm{rpm}$

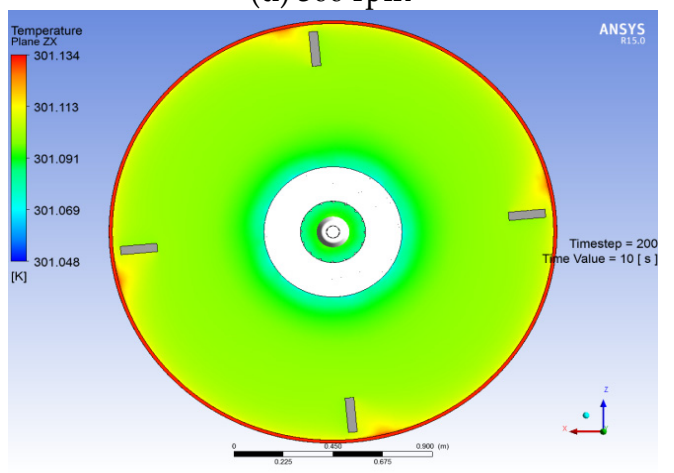

(d) $600 \mathrm{rpm}$

Figure 18. Temperature distribution profiles for KIA impeller homogenizer in ZX plane, for six impeller rotational speeds. 


\subsection{Homogenizer with Pitched Blade Impeller}

The Pitched Blade impeller generates both axial and radial flow in low to medium viscosity fluids, as shown in Figure 5, with a down pumping flow. The impellers produce a higher shear at the blades, which gives a good balance between pumping and shear action for a good general purpose impeller. As shown in Figure 19, the circulation loop is relatively large at the bottom of the homogenizer vessel and around the Pitched Blade impeller, indicating unmixed regions in the homogenizer. The velocity contour in the ZX plane (Figure 20) shows the influence of impeller rotational speed on the homogeneity of the mixture in the homogenizer.

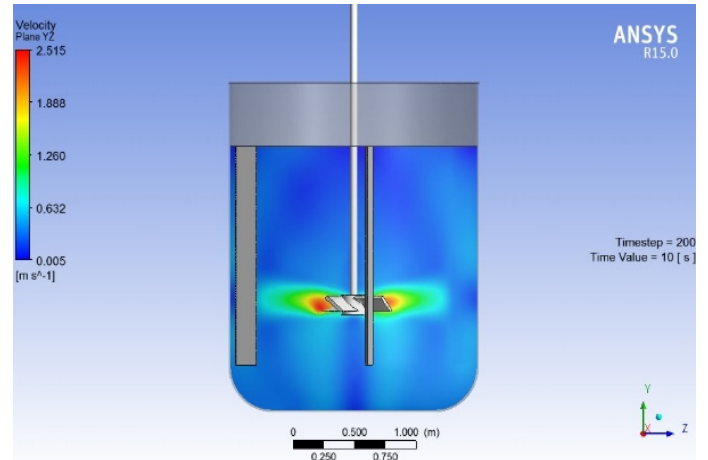

(a) $100 \mathrm{rpm}$

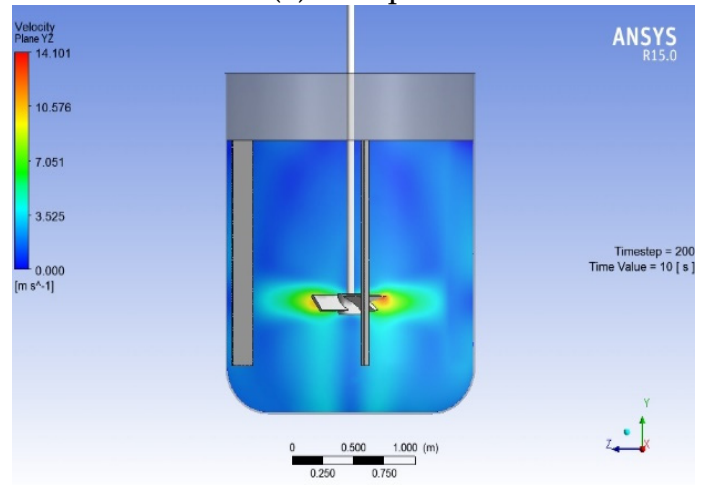

(c) $500 \mathrm{rpm}$

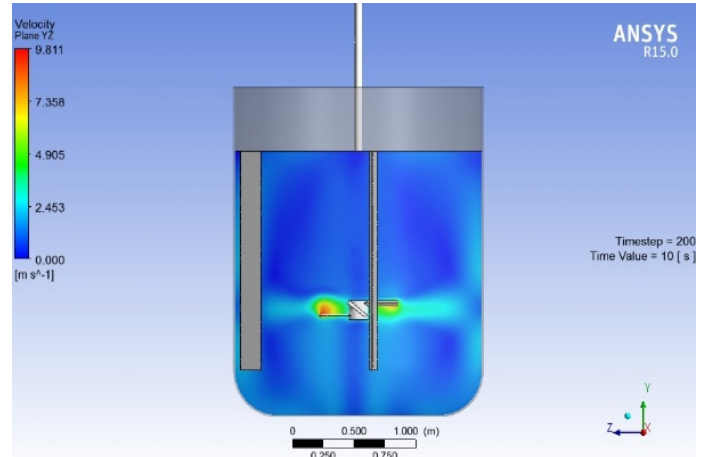

(b) $300 \mathrm{rpm}$

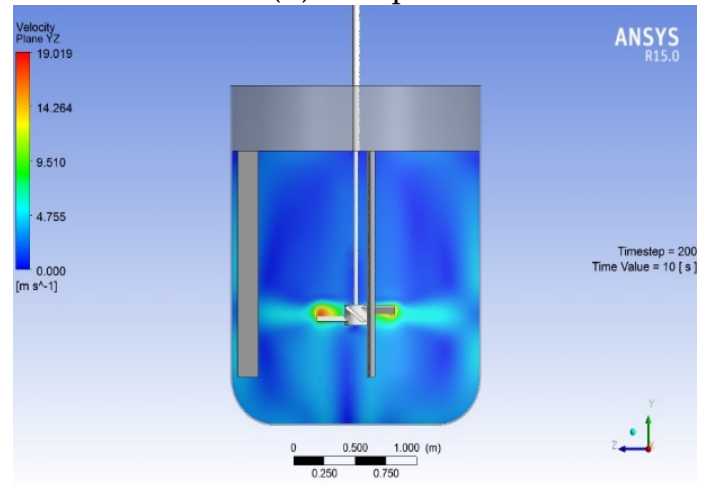

(d) $600 \mathrm{rpm}$

Figure 19. Velocity contour profiles for Pitched Blade impeller homogenizer in $Y Z$ plane, for six impeller rotational speeds.

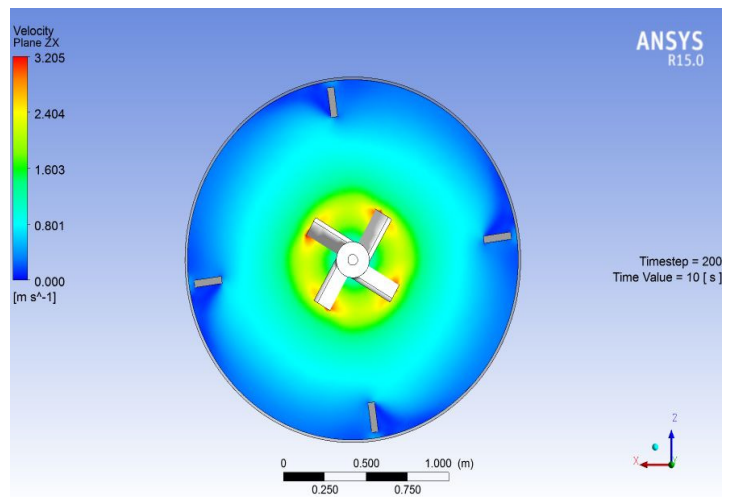

(a) $100 \mathrm{rpm}$

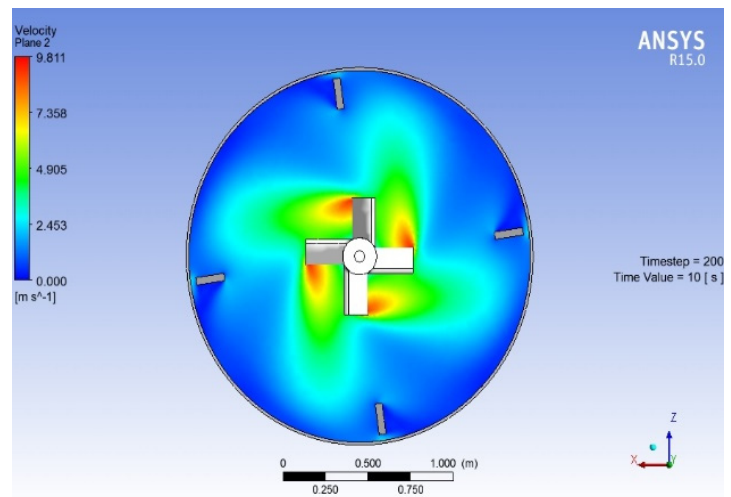

(b) $300 \mathrm{rpm}$

Figure 20. Cont. 


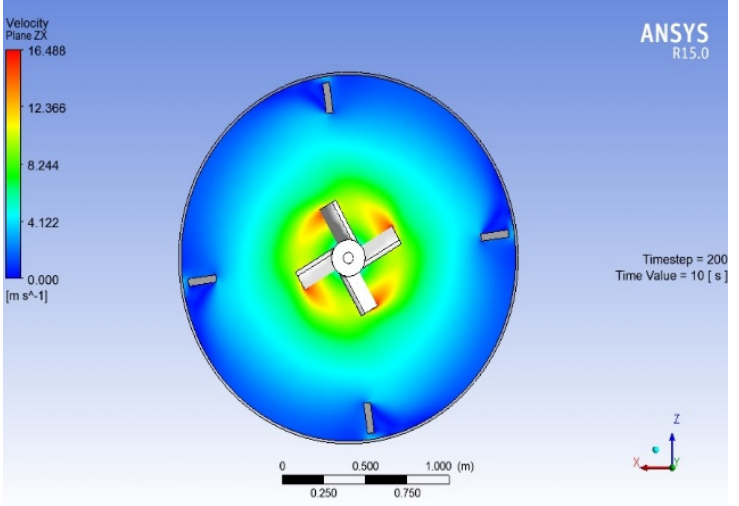

(c) $500 \mathrm{rpm}$

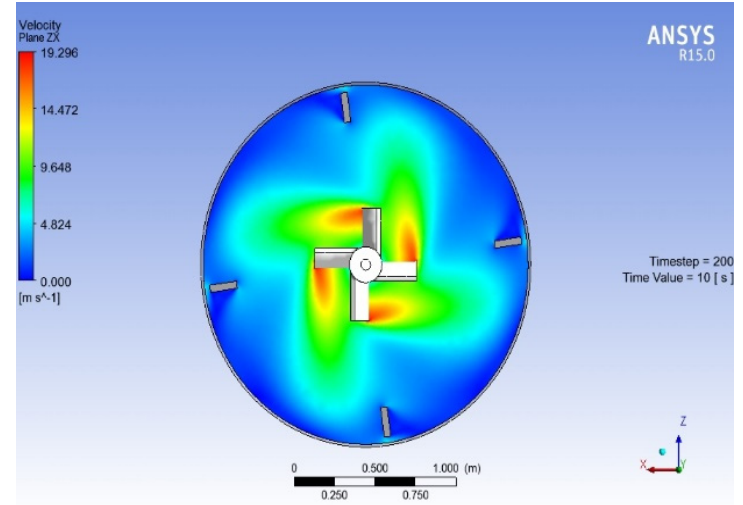

(d) $600 \mathrm{rpm}$

Figure 20. Velocity contours for Pitched Blade impeller homogenizer in ZX plane, for six impeller rotational speeds.

The heat of dissipation from the homogenizer vessel wall to the fluid and also the heat generated by the action of the impeller on the food waste within the Pitched Blade homogenizer are shown in Figures 21 and 22. These contours indicate enhanced heat dissipation as the impeller rotational speed increases (increases from a to d).

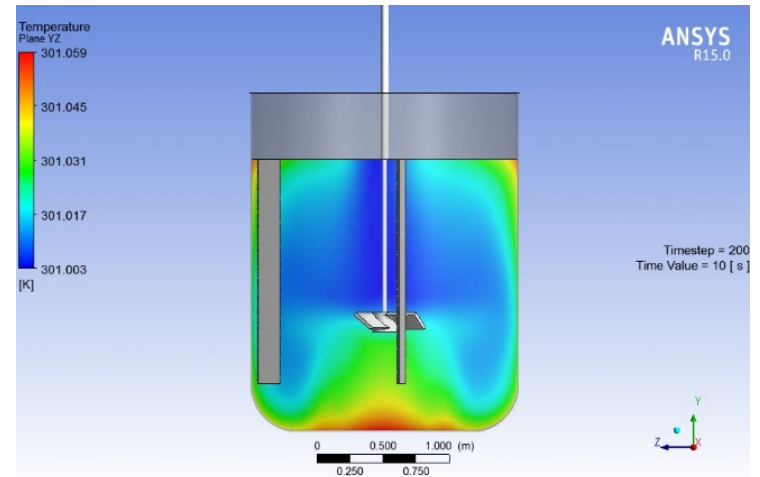

(a) $100 \mathrm{rpm}$

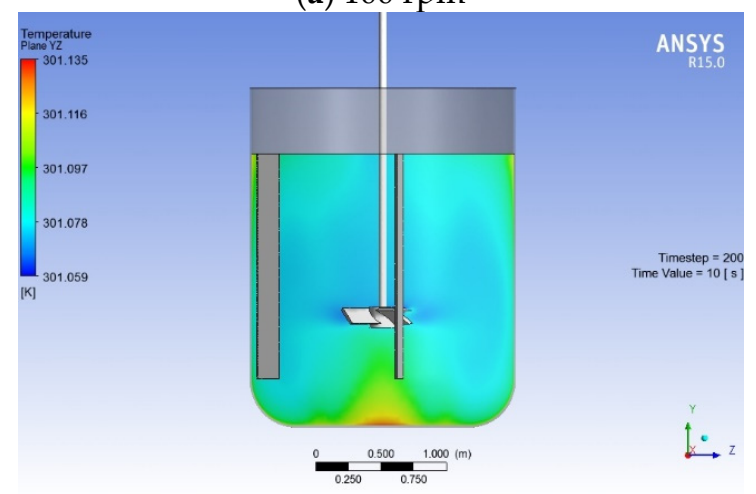

(c) $500 \mathrm{rpm}$

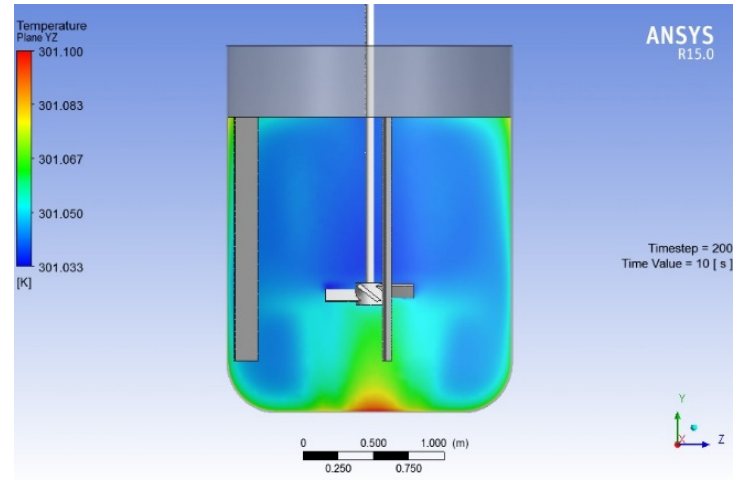

(b) $300 \mathrm{rpm}$

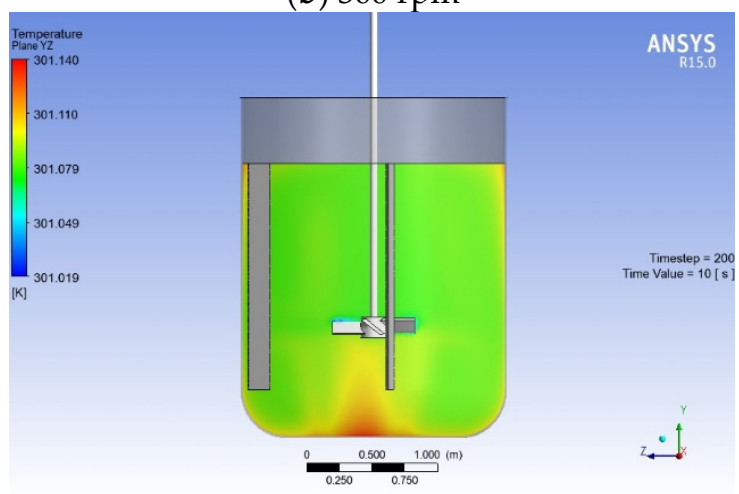

(d) $600 \mathrm{rpm}$

Figure 21. Temperature distribution within Pitched Blade impeller homogenizer in $\mathrm{YZ}$ plane, for six impeller rotational speeds. 


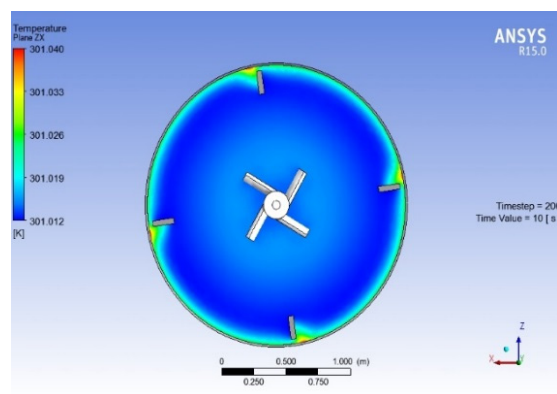

(a) $100 \mathrm{rpm}$

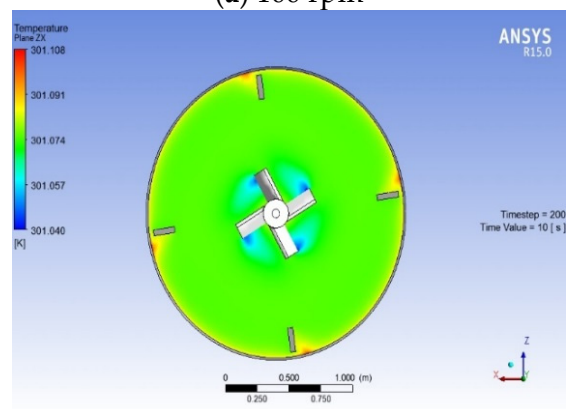

(c) $500 \mathrm{rpm}$

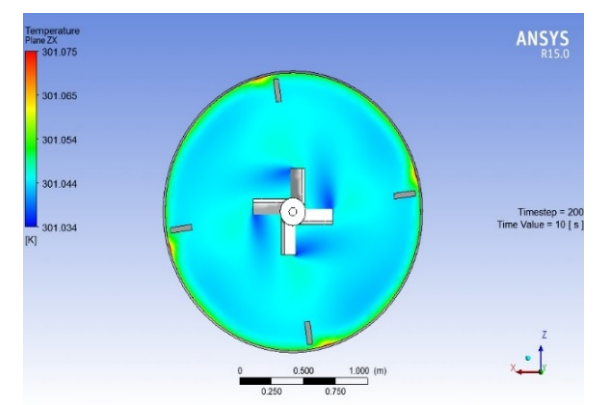

(b) $300 \mathrm{rpm}$

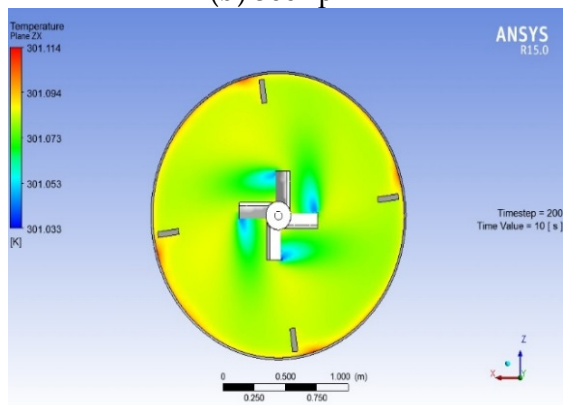

(d) $600 \mathrm{rpm}$

Figure 22. Temperature distributions within Pitched Blade impeller homogenizer in ZX plane, for six impeller rotational speeds.

\subsection{Homogenizer with Anchor Impeller}

The Anchor impeller is a low-speed stirrer impeller used for mixing viscous fluids commonly encountered in biological and polymeric reactors. They are well suited for enhancing the heat transfer rate in viscous fluids, and for placement in an unbaffled homogenizer with small clearances from its wall. Figure 23 shows the velocity vector profile in the XY plane of the Anchor impeller for several rotational speeds imposed on the homogenizer (while the same velocity profile can be viewed in the XZ plane, as shown in Figure 24), the fluid bulk flow of the Anchor impeller is greater compared to other impellers considered in this study because it has a close clearance to the wall and the impeller height is the same as the fluid height in the homogenizer. Mixing is thereby influenced by the large diameter coverage of the impeller as can be evident from Figure 23 for all impeller rotational speeds. At a rotational speed of $600 \mathrm{rpm}$ it is evident from the velocity plot that there are no dead zones within the homogenizer, the Anchor impeller clearance and location within the homogenizer plays an important role on its mixing performance as it offers the best heat and mass transfer rates, the $Y Z$ and $X Y$ planes clearly show the extent of diffusion (mixing) in the homogenizer as the rotational speed is increased from 100 to $600 \mathrm{rpm}$ (increases from a to d).

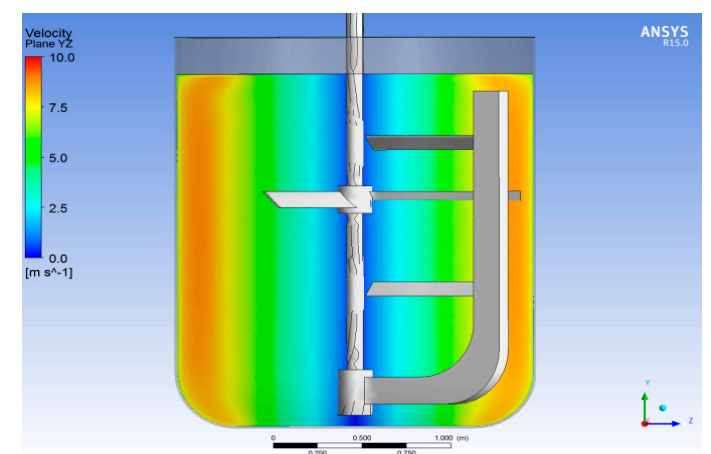

(a) $100 \mathrm{rpm}$

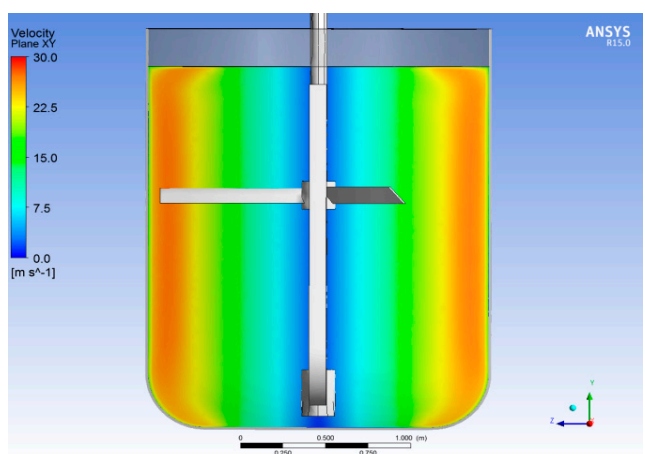

(b) $300 \mathrm{rpm}$

Figure 23. Cont. 


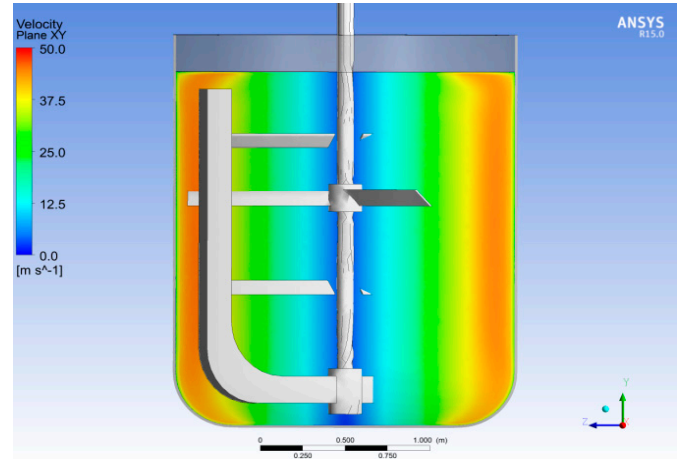

(c) $500 \mathrm{rpm}$

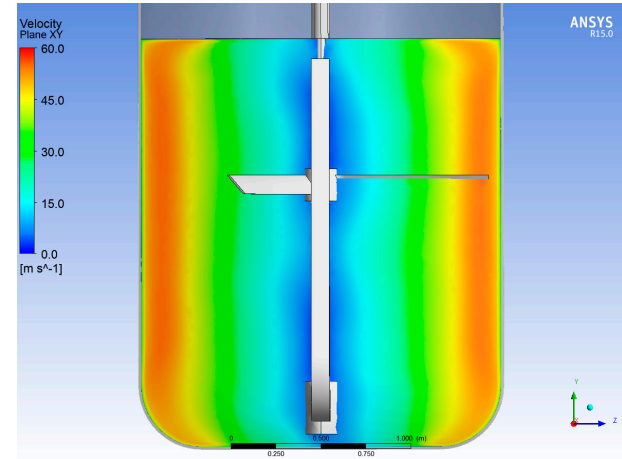

(d) $600 \mathrm{rpm}$

Figure 23. Velocity plots for homogenizer with Anchor impeller in XY plane, for six impeller rotational speeds.

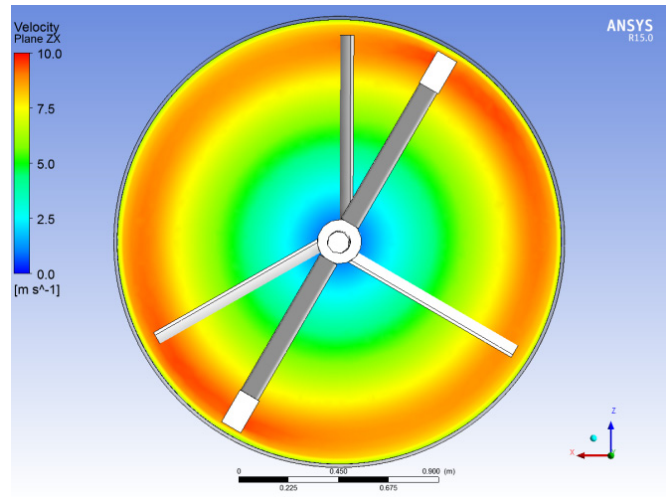

(a) $100 \mathrm{rpm}$

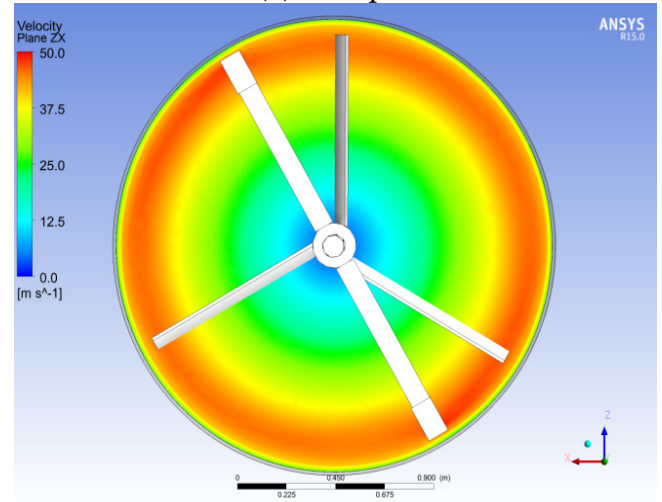

(c) $500 \mathrm{rpm}$

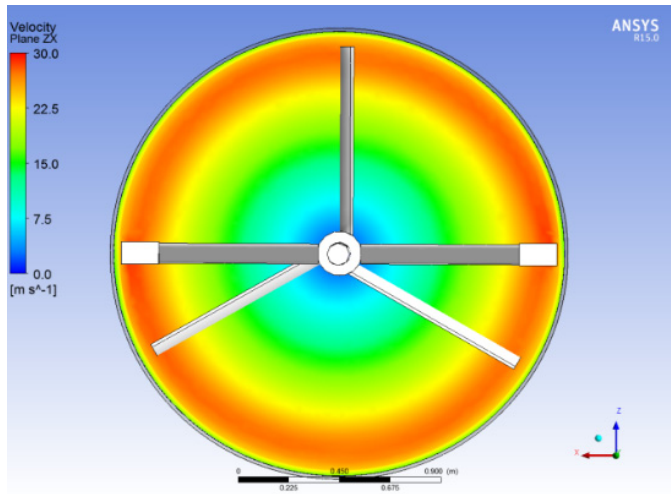

(b) $300 \mathrm{rpm}$

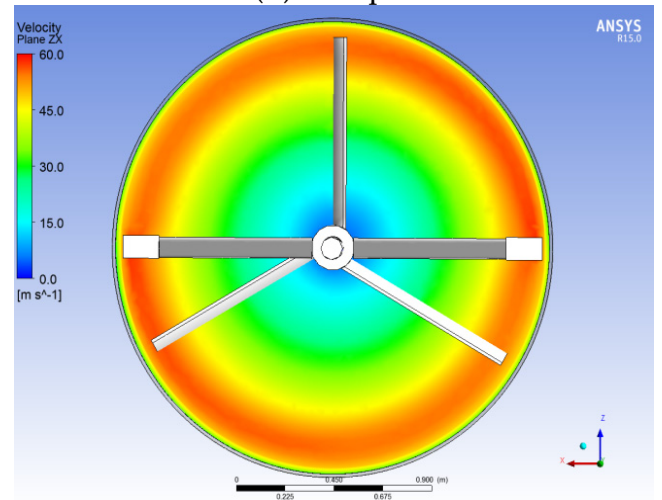

(d) $600 \mathrm{rpm}$

Figure 24. Velocity distributions for Anchor impeller homogenizer in XZ plane, for six impeller rotational speeds.

The temperature distribution plots for the Anchor impeller homogenizer in the YZ plane reveals a dead zone situated at the middle of the homogenizer vessel (see Figure 25), which reduces in size with rotational speed. The heat dissipation in the homogenizer gradually increases for all impeller rotational speeds (increases from a to $\mathbf{d}$ ), thereby enhancing heat transfer from the boundary layer (homogenizer vessel wall) to the fluid domain (carrot-orange soup) within the homogenizer. Figure 26 shows an increasing geometric ratio of heat distribution advantage of the Anchor impeller with an impeller speed over the other three impellers under investigation (increases from a to d). 


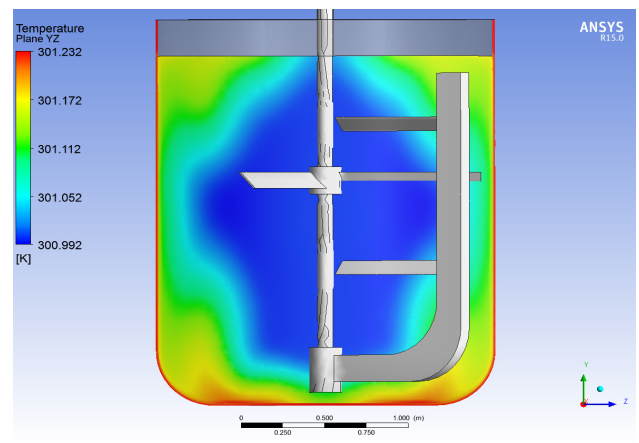

(a) $100 \mathrm{rpm}$

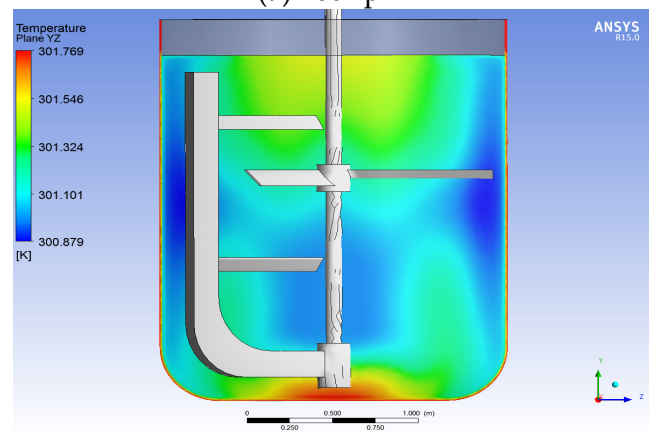

(c) $500 \mathrm{rpm}$

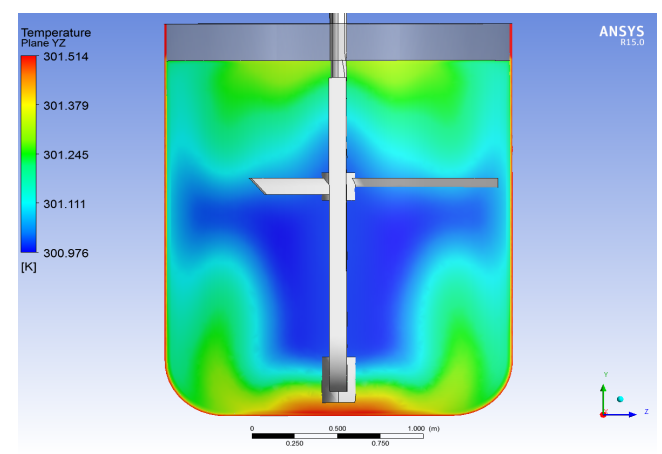

(b) $300 \mathrm{rpm}$

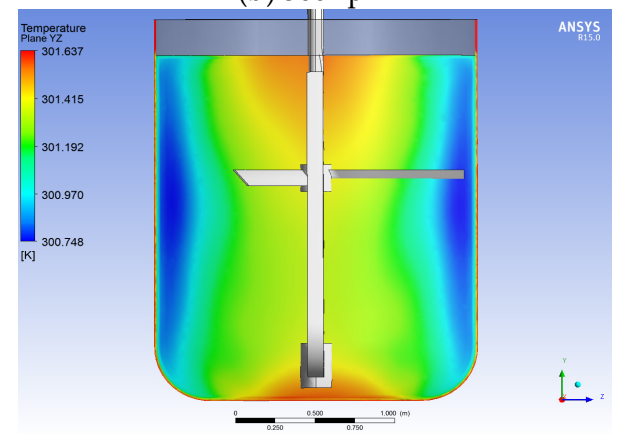

(d) $600 \mathrm{rpm}$

Figure 25. Temperature distribution profile for Anchor impeller homogenizer in YZ plane, for six impeller rotational speeds.

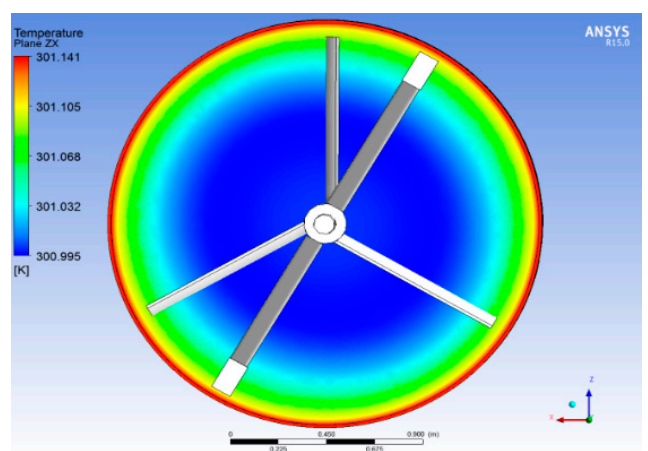

(a) $100 \mathrm{rpm}$

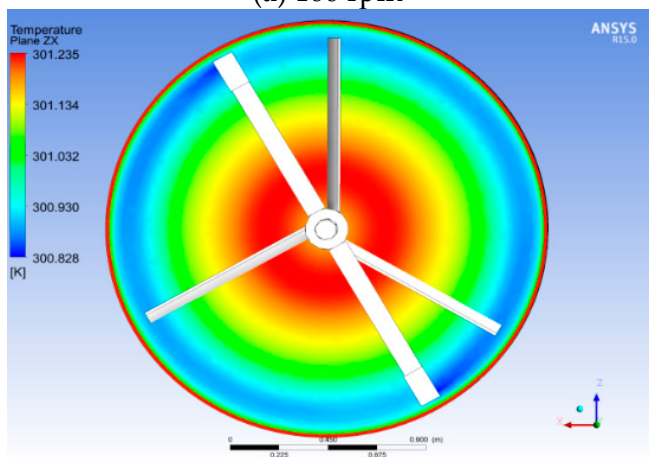

(c) $500 \mathrm{rpm}$

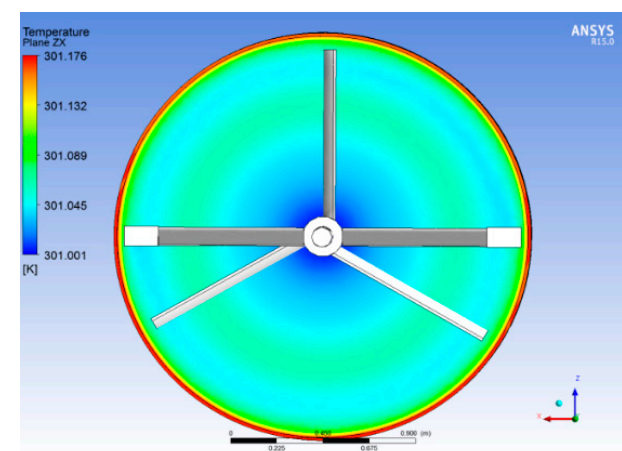

(b) $300 \mathrm{rpm}$

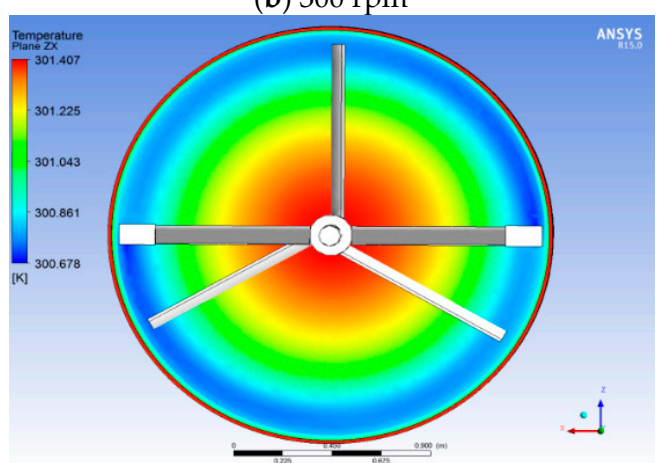

(d) $600 \mathrm{rpm}$

Figure 26. Temperature distributions for Anchor impeller homogenizer in ZX plane, for six impeller rotational speeds. 
Figure 27 compares the rate of thermal diffusion with the impeller rotational speed for all four types of impellers. Although the Anchor impeller appears to have a higher rate of heat dissipation with impeller speed, it is in practice used for low speed operations for mixing of semi-solid materials with low moisture content. The conceptual KIA impeller appears to provide better mixing, compared to both the Rushton and Pitched Blade impellers.

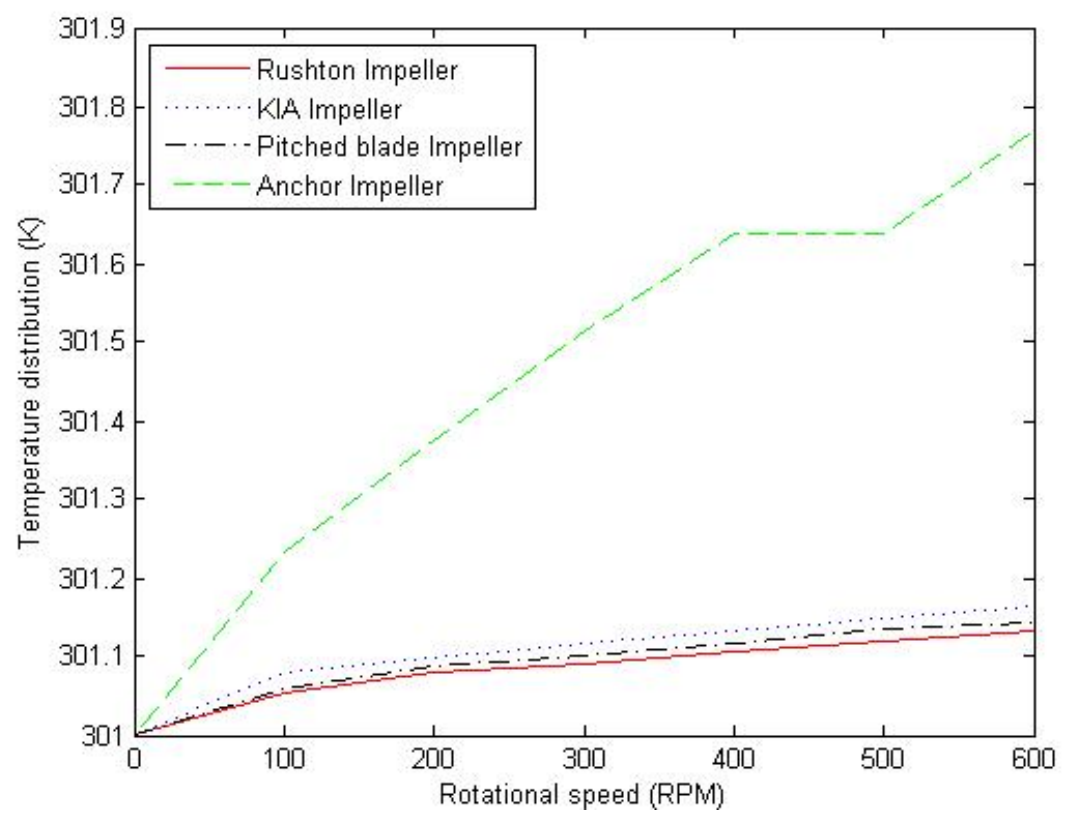

Figure 27. Effects of impeller rotational speed on temperature distribution within the homogenizer.

The cavern diameter in the homogenizer increases with impeller rotational speed. The circulation loop appears to provide the best mixing, especially for the Rushton and Pitched Blade impellers. The use of impact rings in the design for the KIA impeller appears to be the primary reason for the observed overall quantity of mixing within the homogenizer.

\section{Conclusions}

The design of a new impeller called KIA for homogenization of food waste and its subsequent comparative analysis with three conventional impeller types (Rushton, Anchor and Pitched Blade) are carried out using computational fluid dynamics ANSYS CFX v.15.0. The results imply that the KIA impeller improves the overall performance of the six blade Rushton impeller in terms mixing (reduction in the dead zones) capabilities, with increased impeller rotational speed and better heat distribution. The Anchor and Pitched Blade impellers exhibit an overall improvement amongst the impellers studied, apparently due to the use of single phase model approach in simulating the fluid. The homogenizer vessel for the KIA, Pitched Blade and Rushton impellers are equipped with a baffle. The Anchor impeller provides better homogeneity of the fluid (carrot-orange soup) and heat dissipation in the homogenizer, but with a slightly higher power consumption relative to other impellers. This is achieved by the generation of a graphical user interface GUI for motor power selection with the properties of the fluid as a major consideration and geometrical dimensions of the homogenizer, for all cases studied (see Appendix B). Calculations for the shaft design and associated stresses during mixing in a homogenizer, the critical speed and shaft deflection were all considered as this information enables the determination of the operational limit of the homogenizer.

Acknowledgments: Contributions of all research associates, especially those working in the Food Waste Gasifier Assembly Plant group, are appreciated. Efforts of the members of the research review committee towards 
the recommendation of research grant for approval of the University's Central Research Committee (CRC) are acknowledged.

Author Contributions: The paper represents contributions from the M.Sc. research of the first author (Kayode Idris).The homogenizing system simulation is part of the Design of a Homogenizing System for Bio-degradable Food Waste from Eatery centres that is proposed and supervised by the second author (Emmanuel O.B Ogedengbe) at the University of Lagos, Lagos, Nigeria. Extensive advice and critique of the research has been provided by the third author (Marc A. Rosen). All authors read and approved the final manuscript.

Conflicts of Interest: The authors declare no conflict of interest.

\section{Appendix A Municipal Solid Waste generated in five (5) districts in Abuja}

Table A1. Household waste composition for different districts in Abuja.

\begin{tabular}{ccccccc}
\hline \multicolumn{7}{c}{ District names } \\
\hline Waste Type and \% & Garki & Wuse & Maitama & Asokoro & Gwarimpa & Apo \\
\hline Paper & 13 & 12 & 13 & 13.6 & 6.9 & 10.1 \\
Metal & 5.6 & 3.3 & 5.30 & 6.7 & 5.4 & 4.9 \\
Glass & 5.5 & 4.4 & 5.32 & 4.1 & 4.1 & - \\
Plastic & 16.2 & 17.3 & 20 & 15.1 & 21.3 & 18.7 \\
Food remnants & 52 & 54.3 & 54.80 & 53 & 61.2 & 65.3 \\
Textile & 2.2 & 4.7 & 0.10 & 3.1 & - & - \\
Rubber & 3.4 & 1.5 & 0.19 & 0.7 & - & 0.9 \\
Others & 1.8 & 2.4 & 0.60 & 2.8 & 1.1 & - \\
Person/household & 8 & 8 & 6 & 6 & 13 & 6 \\
\hline
\end{tabular}

\section{Appendix B}

MOTOR_POWER

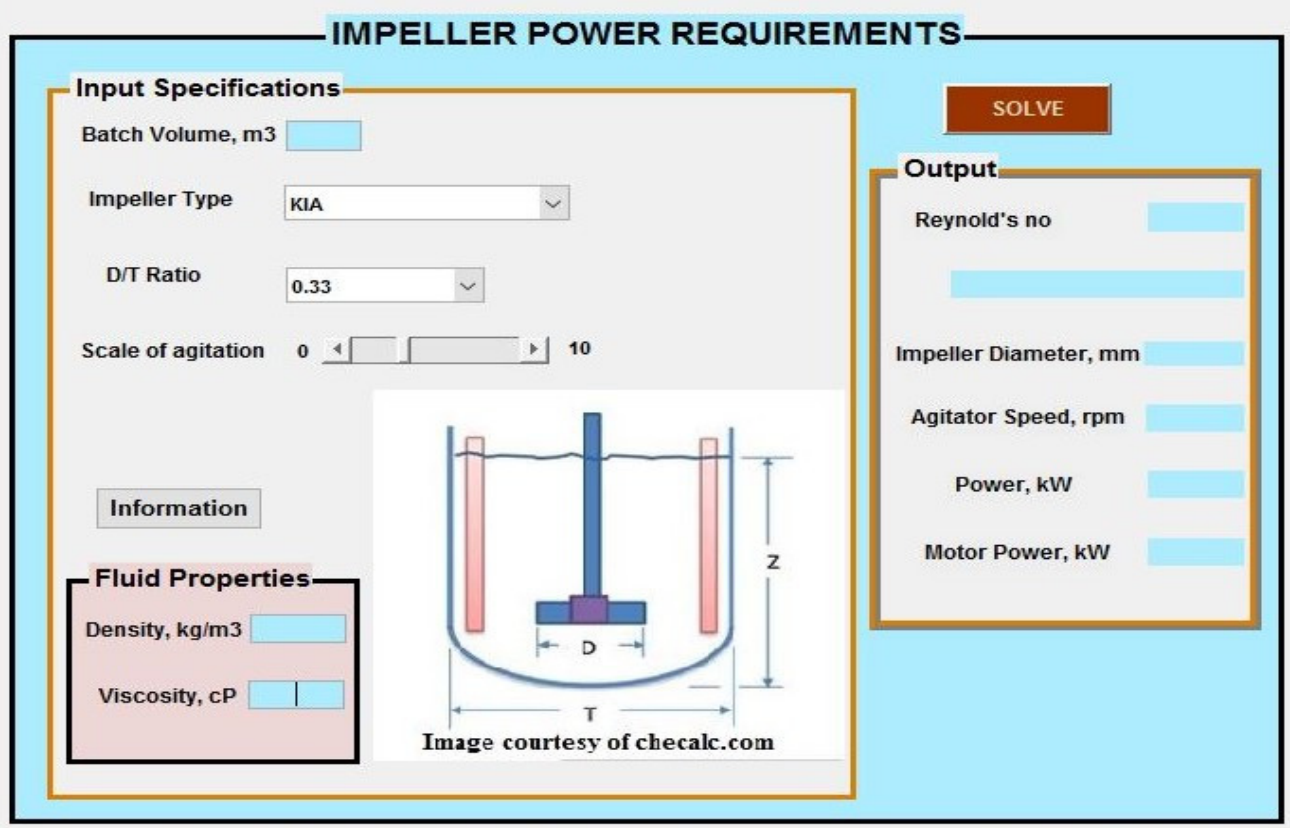

Figure A1. Impeller power requirement GUI. 


\section{Nomenclature}

C - Impeller off bottom clearance ( $\mathrm{mm})$

$C_{v}-$ Volumetric concentrations (-)

$d_{s}-$ minimum shaft diameter $(\mathrm{mm})$

$H$ - Height of homogenizer Vessel (mm)

$k_{s}$ - Effective shear rate estimate $\left(\mathrm{s}^{-1}\right)$

$N_{c}$ - Critical speed of impeller shaft (rpm)

$\mathrm{S}$ - General source term $\left(\mathrm{kgm}^{-3} \mathrm{~s}^{-1}\right)$

$t_{c p u}$ - computer simulation time (s)

$T$ - Homogenizer vessel diameter (mm)

$U_{x}, U_{y}, U_{z}$, Componenets of fluid velocity $(\mathrm{m} / \mathrm{s})$

$U_{x}^{F}, U_{y}^{F}, U_{z}^{F}$ - Components of forcing velocity due to the immersed solid (m/s)

$V$ - Volume of homogenizer vessel $\left(\mathrm{mm}^{3}\right)$

$\beta$ - forcing function (m)

\section{References}

1. Ayuba, K.A.; Manaf, L.A.; Sabrina, A.H.; Azmin, S.W. Current Status of Municipal Solid Waste Practice in FCT Abuja. Res. J. Environ. Earth Sci. 2013, 5, 295-304.

2. Environmental Protection Department. Monitoring of Solid Waste in Hong Kong: Waste Statistics for 2011. Available online: https://www.wastereduction.gov.hk/sites/default/files/msw2011.pdf (accessed on 2 July 2015).

3. Lee, P.K.H.; Lin, C.S.K.; Chan, J.C.L. Turning Food Waste into Treasure. Available online: https://www.cityu. edu.hk/see/news/TurningFoodWasteIntoTreasure.pdf (accessed on 2 July 2015).

4. Ogedengbe, E.O.B.; Kingsley, E.; Eteure, R.U.; Rosen, M.A. Feasibility Study of Cafeteria Energy Demand with Integration of a Downdraft Bio-digester System. In Proceedings of the 10th International Energy Conversion Engineering Conference, Atlanta, Georgia, 30 July-1 August 2012.

5. Babarinsa, O.; Ogedengbe, E.O.B.; Rosen, M.A. Mixing Performance of a Suspended Stirrer for Homogenizing Biodegradable Food Waste from Eatery Centres. Sustainability 2014, 6, 5554-5565. [CrossRef]

6. Akhilesh, K.; Basudeb, M. Numerical comparison of Rushton Turbine and CD-6 Impeller in Non-Newtonian Fluid Stirred Tank. Int. J. Electron. Commun. Eng. 2014, 1, 14-18.

7. Ameur, H.; Bouzit, M.; Helmaoui, M. Numerical Study of Fluid and Power Consumption in a Stirred Vessel with a Scaba 6SRGT Impeller. Chem. Process Eng. 2011, 32, 351-366. [CrossRef]

8. Jirout, T.; Reiger, F. Impeller Design for Mixing of Suspensions. Chem. Eng. Res. Des. 2011, 89, 1144-1151. [CrossRef]

9. Thakur, R.K.; Vial, C.H.; Djelveh, G.; Labbafi, M. Mixing of Complex Fluids with Flat-Bladed Impellers: Effect of Impeller Geometry and Highly Shear Thinning Behavior. Chem. Eng. Process. Process Intensif. 2004, 43, 1211-1222. [CrossRef]

10. Rieger, F.; Jirout, T.; Ceres, D.; Seichter, P. Effects of Impeller Shape on Solid Particle Suspension. Chem. Process Eng. 2013, 34, 139-152. [CrossRef]

11. Monteith, H.D.; Stephenson, J.P. Mixing Efficiencies in Full-Scale Anaerobic Digesters by Tracer Methods. J. Water Pollut. Control Fed. 1981, 53, 78-84.

12. Abbaszadeh, A.; Ghobadian, B.; Najafi, G.; Motevali, A. Analytical and FEM Design of Mixing Systems in STR Biodiesel Production. Adv. Environ. Biol. 2014, 8, 325-334.

13. Asiri, S. Fluid Differential Agitators. Available online: http://waset.org/publications/6310/fluiddifferential-agitators (accessed on 16 May 2106).

14. Kaushal, P.; Sharma, H.K. Concept of Computational Fluid Dyanmics (CFD) and Its Application in Food Processing Equipment Design. J. Food Process Technol. J. Food Technol. 2011. [CrossRef]

15. Guha, D. Hydrdynamics and Mixing in Single Phase and Liquid-Solid Tank Reactors. Ph.D. Thesis, Department of Energy, environmental and chemical Engineering, Washington University, St. Louis, MO, USA, 2007. 
16. Delaplace, G.; Torrez, C.; Andre, C.; Leuliet, J.C.; Belaubre, N. Experimental and CFD simulation of Heat Transfer to Highly Viscous Fluids in an Agitated Vessel Equipped With a Non Standard Helical Ribbon Impeller. Inst. Chem. Eng. Res. Des. 2001, 79, 927-937. [CrossRef]

17. Ghani, A.G.; Farid, M.M.; Chen, X.D. Numerical Simulation of Transient Temperature and Velocity Profiles in a Horizontal Can during Sterilization using Computational Fluid Dynamics. J. Food Eng. 2002, 51, 77-83. [CrossRef]

18. Maingonnat, J.F.; Doublier, J.L.; Lefebvre, J.; Delaplace, G. Power Consumption of a Double Ribbon Impeller with Newtonian and Shear thinning Fluids and during the Gelation of a Iota-Carrageenan Solution. J. Food Eng. 2008, 87, 82-90. [CrossRef]

19. Abdul Ghani Al-Baali, A.G.; Farid, M.M. Sterilization of Food in Retort Pouches (Food Engineering Series); Springer: New York, NY, USA, 2006.

20. Paul, E.L.; Atiemo-Obeng, V.A.; Kresta, S.M. Handbook of Industrial Mixing Science and Practice; Wiley-Interscience: Hoboken, NJ, USA, 2004; pp. 292-302.

21. Kayode, I.A. Design of a Stirrer Impeller with Variable Speed for a Food Waste Homogenizer. Master's Thesis, University of Lagos, Nigeria, 2016.

22. Ranganathan, P.; Savithri, S. Computational Flow Modeling of Multiphase Mechanically Agitated Reactors. In Computational Fluid Dynamics, 1st ed.; Woo, H., Ed.; INTECH: Rijeka, Croatia, 2010.

23. Chara, Z.; Kysela, B.; Konfrst, J.; Fort, I. Study of Fluid Flow in Baffled Vessels Stirred by a Rushton Standard Impeller. Appl. Math. Comput. 2016, 272, 614-628. [CrossRef]

24. Gagnon, H.; Lounès, M.; Thibault, J. Power Consumption and Mass Transfer in Agitated Gas-Liquid Columns: A comparative Study. Can. J. Chem. Eng. 1998, 76, 379-389. [CrossRef]

(C) 2016 by the authors; licensee MDPI, Basel, Switzerland. This article is an open access article distributed under the terms and conditions of the Creative Commons Attribution (CC-BY) license (http:/ / creativecommons.org/licenses/by/4.0/). 